\title{
Relación causal y exclusión de prueba
}

\section{Causal relation and exclusion of evidence}

\author{
Carlos Correa Robles* \\ Dr. Iur. y LL.M. Freie Universität Berlin, \\ Profesor de Derecho Procesal, Universidad Adolfo Ibáñez \\ c.correa@uai.cl
}

\section{Resumen}

El trabajo tiene por finalidad el estudio de la relación de causalidad existente entre la infracción a una regla de obtención probatoria y la exclusión, o respectivamente, la prohibición de valoración de prueba en el proceso penal. Al respecto, la investigación busca delimitar los criterios que permiten tener por acreditada o descartada dicha relación causal en materia probatoria y las consecuencias que se derivan tanto de la ausencia como de la constatación de esta. El análisis propuesto se efectúa desde una perspectiva de derecho comparado, en base al examen de los sistemas jurídicos estadounidense, alemán y chileno, examinando -en cada caso- la doctrina y jurisprudencia pertinente.

Palabras clave: Proceso penal, prueba ilícita, obtención de prueba, causalidad.

\begin{abstract}
This work study the causal relation between the breach of an evidence collection rule and the evidence exclusion, or the prohibition of evidence's assessment within the criminal procedure, respectively. Regarding this point, the research intends to define criteria to prove or to discard said causal relation regarding evidence matters and the consequences arising in the event said relation is proved or not. The proposed analysis uses a comparative law perspective, based in the U.S, German and the Chilean judicial systems, including in each case relevant doctrine and jurisprudence.
\end{abstract}

Keywords: Criminal proceeding, illegal evidence, collection of evidence, causality.

\section{Introducción}

La hipótesis de exclusión probatoria consagrada en el art. 276 inc. $3^{\circ}$, segunda hipótesis del Código Procesal Penal (CPP) permite al juez de garantía excluir en la audiencia de preparación del juicio oral aquellas pruebas que hubieren sido obtenidas con inobservancia de garantías fundamentales. Como se ha sostenido reiteradamente por la doctrina y jurisprudencia chilena, y como se desprende del tenor literal de la disposición mencionada,

\footnotetext{
* Este artículo forma parte de una investigación desarrollada el año 2018 en el marco de un proyecto de investigación interno de la Universidad Adolfo Ibáñez. Mis agradecimientos van en primer lugar a dicha casa de estudio por el apoyo recibido. Agradezco asimismo a Antonio Santelices por la colaboración prestada en el desarrollo de esta investigación y a los dos evaluadores anónimos, por sus valiosas sugerencias y comentarios.
} 


\section{Polít. Crim. Vol. 14, No 28 (Diciembre 2019), Art. 5, pp. 186-214. [http://politcrim.com/wp-content/uploads/2019/11/Vol14N28A5.pdf]}

para que opere dicha exclusión se requiere que la obtención de la prueba cuestionada se encuentre causalmente vinculada con una infracción de garantías fundamentales.

Ahora bien, el sistema de exclusión probatoria escogido por el legislador chileno no resulta a este respecto, ajeno a la realidad comparada. En efecto, en el sistema procesal penal estadounidense la aplicación de la regla de exclusión y de su consecuencia lógica, la teoría de los frutos del árbol envenenado, presuponen asimismo la constatación de una conexión o vínculo causal existente entre una obtención probatoria y la infracción a alguna de las garantías consagradas en diversas enmiendas a la Constitución de dicho país, cuya vulneración autoriza -de acuerdo a la jurisprudencia- la exclusión de prueba.

Ante la ausencia constatable de dicho vínculo causal, la Corte Suprema de dicho país ha considerado aplicable la llamada "excepción de la fuente independiente" (independent source exception), por medio de la cual la inclusión en juicio del medio de prueba cuestionado - primario o secundario- resultará perfectamente válida.

Por otra parte, el modelo de "prohibiciones probatorias" desarrollado en Alemania, prohíbe en primer término la valoración de aquellos medios de prueba en cuya obtención se han transgredido reglas de obtención probatoria. ${ }^{1}$ Para ello, una vez constatada la existencia de la necesaria relación causal, se verificará la concurrencia de los criterios adicionales que finalmente pueden traer como consecuencia una proscripción de valoración probatoria. ${ }^{2}$

Si bien tanto en Chile como en EE.UU. y Alemania, la aplicación de reglas de exclusión y/o de prohibiciones probatorias dependientes presupone la existencia y constatación de un vínculo causal que relacione una diligencia investigativa contraria a derecho con una obtención de prueba, surgen a este respecto diversas interrogantes hasta ahora escasamente abordadas en nuestro país: ¿Qué consecuencias jurídicas generará la ausencia de relación causal en relación a la prueba cuestionada? ¿Qué criterios debe utilizar el tribunal para determinar la existencia o inexistencia de dicho vínculo causal en materia de ilicitud probatoria? ¿Cómo deberán resolverse aquellos casos en los que interviene conjuntamente más de un curso causal en la obtención de la prueba?

El presente trabajo tiene por finalidad responder estas y otras preguntas referidas a la relación de causalidad en materia de ilicitud probatoria, contribuyendo a generar una interpretación coherente del art. 276 inc. $3^{\circ}$ segunda hipótesis CPP, que permita a los actores del sistema procesal penal aplicar reglas claras de actuación frente a casos en los cuales la acreditación y/o relevancia del vínculo causal se muestra especialmente compleja.

La posición que se adopte en relación con las preguntas antes referidas, se encuentra supeditada a la concepción que se tenga de la exclusión de prueba en el proceso penal. En este sentido, el presente trabajo entiende a la averiguación de la verdad como un objetivo central del proceso penal. Así, una sistematización de las distintas situaciones de hecho en

\footnotetext{
${ }^{1}$ Al respecto, vid. CORREA, Carlos, "Más allá de la regla de exclusión: prohibiciones probatorias en el Derecho chileno - con especial referencia al Derecho alemán-", Polit. crim., Vol. 13, Nº 25 (2018), pp. 144174 , pp. 146 y ss.

${ }^{2}$ CORREA, Carlos, "Más allá de la regla de exclusión...”, cit. nota n 1 , pp. 146 y ss.
} 


\section{Polít. Crim. Vol. 14, № 28 (Diciembre 2019), Art. 5, pp. 186-214. [http://politcrim.com/wp-content/uploads/2019/11/Vol14N28A5.pdf]}

las cuales sea posible vincular la obtención de un medio de prueba con (a lo menos) una actuación conforme a derecho, privilegiará la finalidad antes esgrimida en desmedro de la exclusión probatoria.

Para los fines precedentemente indicados, se analizará no solo la doctrina y jurisprudencia chilena, sino que se recurrirá -en primer término- a los ordenamientos comparados ya mencionados, sistemas en los cuales la relación causal en materia probatoria ha sido profusamente tratada. Finalmente se expondrán las conclusiones más relevantes.

\section{El origen y contenido de la regla de exclusión en el derecho estadounidense}

El reciente desarrollo experimentado en Chile en materia de exclusión probatoria, al cual haremos referencia más adelante, habría sido imposible -o al menos hubiese evolucionado en un sentido distinto- de no haber recogido nuestra legislación y jurisprudencia los presupuestos fundamentales de la llamada "regla de exclusión" (exclusionary rule), uno de los desarrollos jurisprudenciales estadounidenses más relevantes en el ámbito procesal penal del último siglo.

A pesar que el estudio exhaustivo de dicha regla y su derivación, la doctrina de los frutos del árbol envenenado, excede el alcance de este trabajo ${ }^{3}$ resulta conveniente explicar brevemente su origen y el rol que desempeña el examen causal como un presupuesto para su aplicación.

Si bien los orígenes de la regla de exclusión se remontan a fines del siglo XIX, ${ }^{4}$ fue en la sentencia Weeks v. U.S. ${ }^{5}$ dictada en 1914, donde la Corte Suprema estadounidense aceptó por vez primera la exclusión de aquellos medios de prueba obtenidos por funcionarios persecutores en contravención a las garantías contenidas en la IV (protección contra detención, allanamiento e incautación ilegal) y con el correr de los años, V (protección contra la autoincriminación y doble persecución), VI (procedimiento justo, fundamentalmente derecho a ser asistido por un abogado) y XIV (debido proceso) enmiendas a la Constitución estadounidense.

\footnotetext{
${ }^{3} \mathrm{Al}$ respecto, entre otros, CORREA, Carlos, "La buena fe del agente como excepción a la aplicación de la regla de exclusión -derecho estadounidense y derecho chileno-", Latin American legal Studies, Vol. 2 (2018), pp. 25-50, pp. 26 y ss.; CORREA, Carlos, "Comentario de sentencia Corte Suprema ingreso número 147812015: efectos reflejos de la prueba obtenida mediante infracción de garantías", Revista de Ciencias Penales, Sexta Época, Vol. 43, № 1 (2016), pp. 159-176, pp. 156 y ss.

${ }^{4}$ Ya el año 1886 la Corte Suprema estadounidense anuló en Boyd v. U.S., 116 U.S. 616, 638 (1886) una sentencia argumentando que el acusado fue coaccionado de un modo ilegítimo a entregar en contra de su voluntad, documentos contables. A este respecto, sostuvo el máximo tribunal que la obtención de material probatorio contraria a la voluntad de su legítimo poseedor, constituye una infracción en contra de la IV y V enmiendas a la Constitución de los EE.UU. que protege a los ciudadanos de allanamientos ilegales y establece una prohibición de autoincriminación. Al respecto, la Corte sostuvo que la evidencia obtenida producto de un ingreso y registro ilegal no constituye prueba en contra de la víctima del allanamiento ilegal. Al respecto, MUELLER, Gerhard, "Beweisverbote im amerikanischen Strafprozeß", en: Comisión permanente de las jornadas alemanas de Derecho Verhandlungen des 46. Deutschen Juristentages, Band I (Gutachten), Teil 3A, München, Berlin: C.H. Beck, 1966, pp. 33-54, p. 40.

${ }^{5}$ Weeks v. U.S., 232 U.S. 383, 398 (1914).
} 


\section{Polít. Crim. Vol. 14, No 28 (Diciembre 2019), Art. 5, pp. 186-214. [http://politcrim.com/wp-content/uploads/2019/11/Vol14N28A5.pdf]}

Presupuesto básico de la aplicación de la regla de exclusión en el sistema estadounidense lo constituye la presencia ineludible de una relación de causalidad entre una infracción de garantías constitucionales y la obtención de un medio de prueba en el marco de una investigación penal. Como sostuvo el máximo tribunal en Mapp v. Ohio "toda la evidencia obtenida por medio de entradas y registros realizados en contravención a la Constitución resulta (...) inadmisible ante una Corte estatal". ${ }^{6}$ Años después afirmaría la misma Corte en Michigan v. Tucker, que la aplicación de la regla de exclusión implica "rechazar aquella evidencia obtenida como resultado de una conducta ilegal". 7 (Énfasis agregado).

\subsection{La excepción de la fuente independiente}

Tras Weeks, en Silverthorne Lumber Co. v. U.S. el máximo tribunal estadounidense se pronunció acerca de la condena emitida por un tribunal inferior en contra del acusado Frederick W. Silverthorne, tras un juicio en el cual se presentaron como evidencia los libros contables encontrados de su oficina durante un allanamiento posteriormente declarado ilegal. Al respecto, resolvió en aquella oportunidad la Corte Suprema que al haberse transgredido la cuarta Enmienda, las pruebas halladas por los agentes como consecuencia del allanamiento ilícito debían ser excluidas del juicio.

Dicha sentencia es hasta el día de hoy recordada, pues a partir de entonces se admite en juicio no sólo la exclusión de aquella prueba directamente obtenida producto de diligencias de investigación que lesionan alguna de las garantías mencionadas, sino además de aquella prueba derivada de tal ilicitud,

"La esencia de una disposición que prohíbe la obtención de pruebas, de cierta manera señala no solo que las pruebas así adquiridas no se utilizarán ante el Tribunal, sino que no se utilizarán en absoluto." 8 (Énfasis agregado)

Tras reconocer en Silverthorne Lumber Co. v. U.S. un efecto reflejo en la aplicación de la regla de exclusión probatoria, el máximo tribunal estadounidense comenzó un largo recorrido dirigido a delimitar el alcance de la mencionada regla, reconociendo progresivamente un conjunto de excepciones a su aplicación.

En efecto, en la misma sentencia en que la Corte extendió por vez primera los efectos de la regla de exclusión a la prueba derivada de la ilicitud, sostuvo igualmente que,

"Desde luego, ello (el reconocimiento de la doctrina de los frutos del árbol envenenado) no significa que la evidencia así obtenida se convierta en algo sagrado e

\footnotetext{
${ }^{6}$ Mapp v. Ohio, 367 U.S. 643, 655 (1961).

7 "By refusing to admit evidence gained as a result of such conduct", Michigan v. Tucker, 417 U.S. 433,447 (1974). Ver también, U.S. v. Peltier, 422 U.S. 531, 539 (1975); Killough v. U.S., 315 F.2d 241 (D.C. Cir. 1962).

8 "The essence of a provision forbidding the acquisition of evidence in a certain way is that not merely evidence so acquired shall not be used before the Court, but that it shall not be used at all". Silverthorne Lumber Co. v. United States, 251 U.S. 385 (1920).
} 


\section{Polít. Crim. Vol. 14, No 28 (Diciembre 2019), Art. 5, pp. 186-214. [http://politcrim.com/wp-content/uploads/2019/11/Vol14N28A5.pdf]}

inaccesible. Si los hechos han sido obtenidos a partir de una fuente independiente ellos pueden ser probados como cualquier otro".

Con dicha frase se reconocía la primera gran excepción a la aplicación de la regla de exclusión probatoria y su derivación lógica, la teoría de los frutos del árbol envenenado: la excepción de la fuente independiente. ${ }^{10}$

El reconocimiento de dicha excepción permite la inclusión (y posterior valoración) en el proceso penal de medios de prueba cuestionados, en tanto resulte posible acreditar que éstos derivan de una fuente independiente. En estos casos, la obtención probatoria cuestionada no se encuentra relacionada (resulta independiente) a una acción antijurídica cometida por la policía; por el contrario, su obtención puede ser reconducida a una actuación conforme a derecho. Como sostuvo la Corte Suprema décadas después, en Wong Sun v. U.S.,

"(1)a regla de exclusión no tiene aplicación en aquellos casos en los que el gobierno ha obtenido la evidencia a partir de una fuente independiente". ${ }^{11}$

En aquellos casos en los que resulte (probatoriamente) posible determinar la presencia de una fuente independiente de la cual provenga el medio de prueba cuestionado, faltará la necesaria relación de causalidad entre la infracción a una garantía constitucional y la obtención de un medio de prueba: ${ }^{12}$ el medio de prueba cuestionado no puede en estos

\footnotetext{
9 "Of course, this does not mean that the facts thus obtained become sacred and inaccessible. If knowledge of them is gained from an independent source they may be proved like any others (...)“ Silverthorne Lumber Co. v. U.S., 251 U.S. 385, 392 (1920). Ver también, Sutton v. U.S., 267 F. 2d 271 (4th Cir. 1959); Burke v. U.S., 328 F. 2d 399 (1st Cir. 1964); Segura v. U.S., 468 U.S. 796 (1984); U.S. v. Crews, 445 U.S. 463 (1980); U.S. v. Wade, 388 U.S. 218, 388 U. S. 242 (1967); Costello v. U.S., 365 U.S. 265, 278-280 (1961); Bynum v. U.S., 274 F. 2d 767 (D.C. Cir. 1960); Lawn v. U.S., 355 U.S. 339, 355 (1958).

10 Vid. AMBOS, Kai, Beweisverwertungsverbote: Grundlagen und Kasuistik - internationale Bezüge ausgewählte Probleme, Berlin: Duncker \& Humblot, 2010, p. 134; CORREA, "La buena fe del agente" cit. nota $\mathrm{n}^{\circ}$ 3, p. 29 y ss.; HARRIS, Kenneth, "Verwertungsverbot für mittelbar erlangte Beweismittel: Die Fernwirkungsdoktrin in der Rechtsprechung im deutschen und amerikanischen Recht", StV (1991), pp. 313322, pp. 315 y 317; OSSENBERG, Sarah, Die Fernwirkung im deutsch-U.S.- amerikanischen Vergleich: unter bedonderer Berücksichtigung der Funktionen der Beweisverwertungsverbote, Hamburg: Kovac, 2011, p. 107; PITSCH, Christoph, Strafprozessuale Beweisverbote: eine systematische, praxisnahe und rechtsvergleichende Untersuchung unter besonderer Berücksichtigung des Steuerstrafverfahrens, der Zufallsfunde und der Fernwirkungsproblematik, Hamburgo: Kovac, 2009, p. 409.

11 "The exclusionary rule has no application (where) the Government learned of the evidence from an independent source."' Wong Sun v. U.S., 371 U.S. 471, 487 (1963). Idéntico criterio se repitió en U.S. v. Houltin, 566 F.2d 1027 (5th Cir.1978). Vid. GOLDEN, Troy E. "The Inevitable Discovery Doctrine Today: The Demands of the Fourth Amendment, Nix, and Murray, and the Disagreement Among the Federal Circuits", B.Y.U. Journal of public law, Vol. 13, N 1 (1998), pp. 97-126, p. 98; JONES, Luther E. Jr., "Fruit of the poisonous tree", S Tex. L. J., Vol. 9 (1967), pp. 17-22, p. 18; KILLIAN, Bobbi J., "United States v. Crews: Fruit of the Poisonous Tree - A new wrinkle?”, Idaho L.Rev., Vol. 18 (1982), pp. 151-162, p. 155; OSSENBERG, Die Fernwirkung, cit. nota n 10, p. 106; ROGALL, Klaus, "\$136a“, en: WOLTER, Jürgen. (Ed.), SK-StPO: Systematischer Kommentar zur Strafprozessordnung. Mit GVG und EMRK, Tomo II: $\$ 94-$ 136a StPO, 5. Ed., Köln: Carl Heymanns Verlag, 2016, pp. 1323-1394, número de párrafo 116.

${ }^{12}$ Por ejemplo, en Bynum v. U.S. 262 F. 2d 465, 468, 469 (D.C. Cir. 1958) fueron declaradas inadmisibles en juicio las huellas digitales obtenidas del imputado tras su detención ilegal, con lo cual el proceso fue finalmente anulado. En el segundo juicio, el ente persecutor fundó su acusación en una serie de huellas
} 


\section{Polít. Crim. Vol. 14, No 28 (Diciembre 2019), Art. 5, pp. 186-214. [http://politcrim.com/wp-content/uploads/2019/11/Vol14N28A5.pdf]}

casos considerarse contaminado con la ilicitud, resultando susceptible de ser valorado por un tribunal penal. ${ }^{13}$

\subsection{Intereses contrapuestos y la aplicación de la excepción de la fuente independiente}

El sistema de exclusión probatoria y sus distintas excepciones se ha desarrollado en el derecho estadounidense a partir de una ponderación de intereses: la correcta averiguación de la verdad (representada por el interés del jurado en orden a contar con toda la evidencia disponible), se contrapone al respeto por las garantías consagradas en diversas enmiendas de la Constitución (representado por el interés de la sociedad en desincentivar conductas reprochables por parte de la policía).

En efecto, como sostuvo el máximo tribunal en Nix v. Williams, ${ }^{14}$ cuando la evidencia cuestionada provenga de una fuente independiente, atendida la falta de vinculación de la obtención probatoria con un acto antijurídico, deberá situarse a la policía en la misma -y no en una peor- posición de la que se encontraría en caso que ningún comportamiento ilícito se hubiese producido. En aquellos casos en los cuales el hecho pueda ser debidamente acreditado en base a prueba lícitamente obtenida, no existirá entonces motivo alguno que impida condenar al imputado. ${ }^{15}$

obtenidas de actas del FBI. Habiéndose nuevamente cuestionado su incorporación, el tribunal las tuvo por admisibles, pues su obtención resulta reconducible a una fuente independiente de la ilicitud y por ello no constituyen un resultado de la misma. Vid. Commonwealth v. Nicholls, 207 Pa. Super. 410, 217 A.2d 768 (1966); OSSENBERG, Die Fernwirkung, cit. nota n 10, p. 106 s.; PITLER, Robert M., "The Fruit of the poisonous Tree" Revisited and Shepardized", Cal. L. Rev., Vol. 56 (1968), pp. 579-651, p. 625; PITSCH, Strafprozessuale Beweisverbote, cit. nota $\mathrm{n}^{\circ}$ 10, p. 378.

${ }^{13} \mathrm{La}$ doctrina de la fuente independiente ha sido reconocida expresamente como aplicable por parte de nuestra Corte Suprema. Al respecto, en sentencia ingreso Nr. 49.714-2016, Cons. $5^{\circ}$ se resolvió, "Que, la jurisprudencia norteamericana ha ido reconociendo ciertos límites al principio de exclusión referido del fruto del árbol envenenado, sobre todo por la vía de precisar las características del vínculo causal que ha de existir entre la infracción constitucional y la obtención de las pruebas cuya exclusión se reclama. Una de dichas excepciones corresponde a la doctrina de la fuente independiente, la que ha sido aceptada incluso cuando ésta aparece con posterioridad a la actuación ilegal inicial, debido a que en estos casos la prueba obtenida no es un "fruto" de la ilicitud. Esto ya lo reconocía la sentencia del caso Silverthorne (251 U.S. 385, 1920) cuando aclaraba que el fundamento de la exclusión de prueba y sus amplios efectos no volvía los hechos investigados sagrados o inaccesibles, pues si se adquiría conocimiento de tales hechos mediante una fuente independiente, éstos podrían ser probados como cualesquiera otros hechos. (Hernández, "La exclusión de la prueba ilícita en el nuevo Proceso Penal chileno", Colección de Investigaciones Jurídicas, Universidad Alberto Hurtado, 2002 $\mathrm{N}^{\circ} 2$, p. 22).

La doctrina cita como ejemplos claros de pruebas obtenidas a través de una fuente independiente los casos en que la evidencia se obtiene con anterioridad al acto calificado de ilegal, hipótesis ésta que corresponde a la situación de autos, según aparece del mérito de la sentencia impugnada. (...) siempre será posible fundar con cierta facilidad una relación de causalidad entre la actuación ilícita y las restantes diligencias de investigación y, con ello, fundar la necesidad de exclusión de todo el material probatorio disponible. (Hernández, cit. p. 77)".

14 "the interest of society in deterring unlawful police conduct and the public interest in having juries receive all probative evidence of a crime are properly balanced by putting the police in the same, not a worse, position that they would have been in if no police error or misconduct had occurred (...). When the challenged evidence has an independent source, exclusion of such evidence would put the police in a worse position than they would have been in absent any error or violation": Nix v. Williams, 467 U.S. 431, 443 (1984). Vid. Además, Murray v. U.S., 487 U.S. 533, 537 (1988).

${ }^{15}$ Sutton v. U.S., 267 F. 2d 271, 272 (4th Circuit 1959). 


\section{Polít. Crim. Vol. 14, No 28 (Diciembre 2019), Art. 5, pp. 186-214. [http://politcrim.com/wp-content/uploads/2019/11/Vol14N28A5.pdf]}

De este modo, habiendo sido el medio de prueba cuestionado obtenido conforme a derecho, no resultará necesario disuadir a la policía de cometer nuevas infracciones de garantías al momento de obtener la prueba. ${ }^{16}$ El fundamento mismo de la exclusión probatoria en los Estados Unidos -el conocido deterrence- perderá su razón de ser.

\section{La relación causal y su relevancia en el sistema de prohibiciones de valoración probatorias dependientes en el derecho alemán}

La relevancia de la relación causal constituye un elemento central en el tratamiento de la prueba ilícita en Alemania, problema desarrollado en dicho país a partir de la teoría de las prohibiciones probatorias. ${ }^{17}$ En términos generales, por medio de las "prohibiciones de valoración de prueba dependientes" (unselbständige Beweisverwertungsverbote) se busca proscribir ciertos elementos probatorios de la valoración de prueba a cargo del tribunal. Dichas prohibiciones se originan a partir de la contravención por parte de agentes policiales de reglas de obtención probatoria, cometida al momento de recabar material incriminatorio.

Ahora bien, sin perjuicio de la compleja (y controvertida) determinación de los criterios materiales que permiten delimitar aquellos casos en los cuales la infracción a una regla de obtención probatoria generará como consecuencia una prohibición de valoración de la prueba así obtenida, de aquellos casos en los que la infracción a reglas de obtención restará procesalmente impune, ${ }^{18}$ la presencia de una relación causal entre la obtención de un medio de prueba cuestionado y la infracción a una regla de producción probatoria, constituye -de acuerdo a la doctrina mayoritaria- un presupuesto básico de existencia de las prohibiciones de prueba dependientes. ${ }^{19}$

De este modo, cuando el elemento probatorio cuestionado ha sido obtenido gracias a una diligencia investigativa efectuada conforme a la ley, no resultará posible configurar una infracción a reglas de producción probatoria, que posteriormente -y previo cumplimiento de requisitos adicionales- podría dar lugar al reconocimiento de una prohibición probatoria dependiente.

Dicha conclusión se extiende en Alemania al reconocimiento de prohibiciones de prueba derivada o secundaria: la obtención de un medio de prueba, causalmente vinculada a otro medio de prueba no susceptible de valoración, constituye un requisito de existencia de la

${ }^{16}$ Cfr. HARRIS, "Verwertungsverbot für mittelbar erlangte Beweismittel" cit. nota $\mathrm{n}^{\circ} 10$, p. 316; OSSENBERG, Die Fernwirkung, cit. nota ${ }^{\circ}$ 10, p. 106.

${ }^{17} \mathrm{Al}$ respecto, pormenorizadamente, CORREA, "Más allá de la regla de exclusión" cit. nota n 1 , pp. y 146 ss.

${ }^{18} \mathrm{Al}$ respecto, CORREA, "Más allá de la regla de exclusión" cit. nota n 1, pp. y 149 ss.

${ }^{19}$ Por todos, LÖWE, Ewald, ROSENBERG, Werner, ERB, Volker, ESSER, Robert, FRANKE, Ulrich, GRAALMANN-SCHEERER, Kirsten, HILGER, Hans, IGNOR, Alexander, GERBER, Friederike, Die Strafprozeßordnung und das Gerichtsverfassungsgesetz: Großkommentar, Berlin; New York: de Gruyter, 2016, § 136 a, número al margen 70; KELNHOFER, Evelyn, Hypothetische Ermittlungsverläufe im System der Beweisverbote, Berlin: Duncker \& Humblot, 1994, p. 100; REINECKE, Jan, Die Fernwirkung von Beweisverwertungsverboten, München: VVF, 1990, p. 52; SCHRÖDER, Svenja, Beweisverwertungsverbote und Hypothese rechtmäßiger Beweiserlangung im Strafprozeß, Berlin: Duncker \& Humblot, 1992, pp. y 76 s. 


\section{Polít. Crim. Vol. 14, No 28 (Diciembre 2019), Art. 5, pp. 186-214. [http://politcrim.com/wp-content/uploads/2019/11/Vol14N28A5.pdf]}

prueba secundaria, cuya valoración en juicio resultará igualmente prohibida. ${ }^{20}$ Sólo será posible hablar de prohibiciones de prueba secundarias, cuando la infracción normativa que conduce a la obtención de un medio de prueba primario, resulte a su vez causante de la obtención de prueba secundaria. ${ }^{21} \mathrm{Si}$ los antecedentes del caso permiten descartar dicha vinculación, será la obtención del medio de prueba jurídicamente irreprochable y con ello susceptible de valoración.

En este sentido, ya en 1956 sostenía acertadamente Sendler, ${ }^{22}$ en una de las primeras monografías dedicadas al estudio de las prohibiciones probatorias, que,

“(...) la valoración de otros medios de pruebas vinculados con una vulneración al $\S$ 136a $\mathrm{StPO}^{23}$ se comprende dentro de la prohibición contenida en dicha disposición. Ello no será el caso cuando el medio de prueba cuestionado hubiera sido obtenido con independencia de la declaración defectuosa (...)“.

En concordancia con lo sostenido precedentemente, la jurisprudencia alemana ha reconocido reiteradamente la existencia de una relación de causalidad como un presupuesto básico para sostener la existencia o inexistencia de una prohibición probatoria.

Así, el Tribunal Estadual Superior de Colonia (OLG Köln) ha concluido que todos aquellos medios de prueba obtenidos a causa (aufgrund) de una interceptación telefónica llevada a cabo en contravención con los requisitos establecidos por el legislador, no resultan susceptibles de ser valorados por un tribunal con competencia en lo penal. ${ }^{24}$

Asimismo, el Tribunal Supremo alemán ha sostenido a contrario sensu en BGHSt 27, 355 (358) que aquellas declaraciones obtenidas por medio de una interceptación telefónica, no vinculadas causalmente a una infracción al $\S 100$ a) $\mathrm{StPO}^{25}$ constituyen una fuente de conocimiento independiente de la ilicitud y que por ello pueden ser válidamente utilizadas en el procedimiento. ${ }^{26}$

Por último, el mismo Tribunal Supremo ha sostenido en BGHSt 29, 244 (252) que la presencia de una relación causal entre una interceptación ilegal de correspondencia y la obtención probatoria cuestionada, ha permitido demostrar la relación del medio de prueba objetado con la ilicitud, impidiendo ello su valoración por parte de un tribunal penal.

\footnotetext{
${ }^{20}$ Cfr. REINECKE, Die Fernwirkung von Beweisverwertungsverboten, cit. nota $\mathrm{n}^{\circ} 19$, p. 56.

${ }^{21}$ Cfr. FEZER, Gerhard, Strafprozeßrecht, 2a Ed., München: Juristischer Studienkurs, 1995., Caso Nr. 16, número al margen 50; REINECKE, Die Fernwirkung von Beweisverwertungsverboten, cit. nota $\mathrm{n}^{\circ} 19$, p. 52 ss.; SCHRÖDER, Beweisverwertungsverbote und Hypothese, cit. nota $\mathrm{n}^{\circ}$ 19, p. 76.

22 SENDLER, Horst, Die Verwertung rechtswidrig erlangter Beweismittel im Strafproze $\beta$ mit Berücksichtigung des anglo-amerikanischen und des französischen Rechts, Freie Universität Berlin, inédito, 1956, p. 49.

${ }^{23}$ Prohibición de utilizar métodos de interrogatorio prohibidos.

${ }^{24}$ OLG Köln NJW 1979, 1216 (1217).

${ }^{25}$ Establece los requisitos de procedencia para ordenar la interceptación de telecomunicaciones en el marco de un procedimiento penal.

${ }^{26}$ Vid. además, BGHSt 29, 244 (248).
} 


\section{Polít. Crim. Vol. 14, No 28 (Diciembre 2019), Art. 5, pp. 186-214. [http://politcrim.com/wp-content/uploads/2019/11/Vol14N28A5.pdf]}

\section{La relación de causalidad y la exclusión probatoria en el derecho chileno}

Tal como sucede en los ordenamientos ya analizados, la exclusión de prueba en el proceso penal chileno se encuentra íntimamente relacionada con la constatación de un nexo de causalidad. En efecto, la presencia de un vínculo entre la obtención de un medio de prueba y la infracción de garantías, constituye un presupuesto esencial para configurar el supuesto de exclusión de prueba consagrado en el art. 276 inc. $3^{\circ} \mathrm{CPP}^{27}$ (prueba obtenida con inobservancia de garantías fundamentales).

La relevancia del vínculo de causalidad en materia de prueba ilícita en el sistema chileno, no se agota en el tenor literal de la referida disposición. Por el contrario, si se asume como la finalidad última de la regla de exclusión probatoria, el resguardo de garantías fundamentales en el proceso penal, ${ }^{28}$ resulta necesario reconocer (ya fuera del alcance directo de la regla de exclusión), tanto en la etapa de investigación como de juicio oral, mecanismos destinados a dotar de ineficacia procesal a aquellos elementos probatorios ilícitamente obtenidos y sometidos a la valoración del tribunal. A nuestro juicio, la solución a dichos problema pasa -como señalé en otra oportunidad ${ }^{29}$ - por reconocer la existencia residual de prohibiciones de valoración de prueba obtenida con infracción de garantías (en el sentido antes referido al tratar el modelo alemán), con eficacia fuera de la audiencia de preparación del juicio oral. Sólo por medio del reconocimiento de estas prohibiciones, podrá satisfacerse cabalmente la finalidad antes indicada en todas las etapas del proceso penal.

El reconocimiento residual de prohibiciones de valoración de prueba en el proceso penal chileno, aplicable tanto a decisiones adoptadas por el órgano adjudicador en la etapa de investigación como en el juicio oral, requiere igualmente para su constatación la presencia de un vínculo causal entre una obtención probatoria y una actuación policial contraria a derecho.

Igualmente, la existencia de la comentada relación causal resulta determinante en nuestro sistema para sustentar un efecto reflejo o derivado de la ilicitud. Como se ha sostenido, la relación de la prueba cuestionada con otros elementos, a su vez vinculados causalmente con una infracción de garantías, configura la existencia de prueba derivada, cuyo reconocimiento posibilitará -en principio- su exclusión ${ }^{30}$ o bien la prohibición de su valoración. $^{31}$

\footnotetext{
${ }^{27}$ CAROCCA, Alex, "Una primera aproximación al tema de la prueba ilícita en Chile", Ius et Praxis, vol. 4 No 2 (1998), pp. 301-322, p. 306; HERNANDEZ, Héctor, Exclusión de la prueba ilícita en el nuevo proceso penal chileno. Santiago: Universidad Alberto Hurtado, 2005, p. 51 s.

28 En este sentido, ZAPATA, Francisca, La prueba ilícita, Santiago: Lexis Nexis, 2004, p. 50; ECHEVERRIA, Isabel, Los derechos fundamentales y la prueba ilícita: con especial referencia a la prueba ilícita aportada por el querellante particular y por la defensa, Santiago: Eds. Jurídicas de Santiago, 2010, p. 27.

${ }^{29}$ CORREA, "Más allá de la regla de exclusión” cit. nota n 1, pp. 154 y 167.

${ }^{30}$ Cfr. HERNANDEZ, Exclusión de la prueba ilícita, cit. nota ${ }^{\circ}$ 27, p. 77; ZAPATA, La prueba ilícita, cit. nota $\mathrm{n}^{\circ} 28$, p. 32.

${ }^{31}$ Vid. CORREA, "Más allá de la regla de exclusión” cit. nota $n^{\circ} 1$, pp. 155 y ss.
} 


\section{La relación de causalidad y la exclusión probatoria en la jurisprudencia de los tribunales superiores chilenos}

La necesidad de acreditar el vínculo de causalidad, como un presupuesto de aplicación de la regla de exclusión probatoria ha sido reconocida reiteradamente por la jurisprudencia de nuestra Corte Suprema al momento de resolver acerca de la procedencia del recurso de nulidad por infracción de derechos o garantías, causal contemplada en el art. 373 letra a) del CPP, ${ }^{32}$ o bien, por parte de las Cortes de Apelaciones al resolver apelaciones interpuestas por el Ministerio Público en contra del auto de apertura del juicio oral por errónea exclusión de prueba en la etapa intermedia. En concreto, los recursos que a lo largo de esta sección se analizan, discurren sobre una misma problemática: la discusión acerca de la (pretendidamente errónea) incorporación y eventual posterior valoración de medios de prueba supuestamente obtenidos con infracción de garantías por parte del tribunal de fondo. Es justamente a este respecto, donde el examen de causalidad cobra relevancia práctica.

En sentencia ingreso Nr. 21.413-14 (Cons. $8^{\circ}$ y $9^{\circ}$ ) el máximo tribunal se pronunció sobre la licitud de la evidencia incautada con motivo del ingreso y registro a un inmueble en una forma no autorizada por la ley. Al respecto, sostuvo la Corte que habiendo los funcionarios excedido las posibilidades de actuaciones que les reconoce la ley "y dada la relación causal entre la diligencia censurada y la prueba de cargo obtenida", resulta necesario dar lugar al recurso interpuesto.

Del mismo modo, en sentencia ingreso Nr. 372-2014, la Corte de Apelaciones de Arica resolvió excluir del auto de apertura del juicio oral los medios de prueba cuestionados por la defensa, argumentando que su obtención se encuentra causalmente vinculada con la detención de la imputada, previamente declarada ilegal (Cons. 8). A contrario sensu, descartó la Corte la exclusión de aquellas probanzas obtenidas con posterioridad a la detención ilegal y que -pese a ello- "no derivaban directamente de aquella".

Posteriormente, la Corte Suprema sostuvo en sentencia ingreso Nr. 14.781-15 (Cons. $8^{\circ}$ ), que para resolver sobre la inclusión de un medio de prueba derivado de la ilicitud, resulta necesario determinar si los medios de prueba impugnados "pueden o no considerarse consecutivos o dependientes del acto cuya ilicitud ha sido afirmada".

En un sentido similar, la Corte de Apelaciones de Antofagasta sostuvo en sentencias ingreso Nr. $184-05$, Cons. $6^{\circ}$, y $92-08$, Cons. $7^{\circ}$, que el alcance de la prueba ilícita afectará a aquellos elementos probatorios obtenidos por los aprehensores con ocasión de un procedimiento viciado, ${ }^{33}$ de manera tal que no es dable utilizar "ninguna prueba que tenga su origen en aquélla que hubiere sido obtenida en forma contraria a la ley, puesto que existe un nexo causal que lo impide".

Asimismo, la Corte de Apelaciones de Concepción ha sostenido que para admitir una exclusión probatoria "se requiere que la infracción legal (ilicitud de base) se pueda vincular

\footnotetext{
${ }^{32}$ Recientemente y sin perjuicio de las otras sentencias citadas en este trabajo, Corte Suprema ingreso Nr. 92.878-2016 (Cons. $7^{\circ}$ ); 8332-2018 (Cons. 5); 19.008-2017 (Cons. 12º); 39.475-2016 (Cons. 12 y s.).

${ }^{33} \mathrm{El}$ imputado fue detenido ilegalmente.
} 


\section{Polít. Crim. Vol. 14, No 28 (Diciembre 2019), Art. 5, pp. 186-214. [http://politcrim.com/wp-content/uploads/2019/11/Vol14N28A5.pdf]}

con una garantía fundamental que pueda conceptualizarse en una afectación de la misma". Sentencia ingreso Nr. 287 2014, razonamiento reiterado en ingresos Nr. 709-2017; 9032016.

En general, en relación a los efectos que conlleva acoger el recurso de nulidad interpuesto por la causal contemplada en el art. 373 letra a) CPP, de manera reiterada la Corte Suprema ha ordenado excluir del nuevo juicio oral aquellos elementos de prueba causalmente vinculados con el vicio que generó la nulidad del primer juicio y de la sentencia. En ese sentido, recientemente los ingresos de la Corte Suprema Nr. 6067-2018, Cons. $7^{\circ}$; 79832018, Cons. $7^{\circ}$; Nr. 88.862-2016, Cons. $9^{\circ}$ y Nr. 35.555-2016, Cons. $14^{\circ}$.

\section{La ausencia de vínculo causal en el derecho chileno}

De acuerdo a lo analizado, resulta ya posible concluir que descartada sea la presencia de una relación causal entre una actuación de investigación atentatoria de garantías y la obtención de material probatorio, faltará un presupuesto básico para considerar la prueba cuestionada como ilícita. ${ }^{34}$ En este sentido, huelga señalar que la ausencia de relación causal entre ilicitud y obtención probatoria, más que constituir una excepción a la regla de exclusión, configura una verdadera falta de presupuestos materiales para su procedencia. Siendo en estos casos la prueba cuestionada reconducible a una actuación jurídicamente irreprochable (o al menos, no atentatoria de garantías fundamentales), esta no podrá considerarse contaminada.

Asimismo, como ha sostenido la doctrina mayoritaria en Chile, ${ }^{35}$ cabe desestimar un efecto reflejo de la exclusión probatoria en aquellos casos en los cuales el medio de prueba cuestionado no se encuentra causalmente vinculado a un medio de prueba primario susceptible de ser excluido en el auto de apertura o, respectivamente, de ser valorado. Lo recién expuesto ha sido sostenido igualmente por la Corte Suprema chilena, tribunal que ante la ausencia de vínculo causal reconoce la aplicación de la ya analizada excepción de la fuente independiente. ${ }^{36}$

Al respecto, y en relación a la valoración de un medio de prueba cuya obtención no resulta reconducible a una diligencia investigativa antijurídica, sostuvo el máximo tribunal en sentencia ingreso Nr. 2333-10, citando a Hernández, que en la especie concurre la doctrina

\footnotetext{
${ }^{34}$ Cfr. HERNANDEZ, Exclusión de la prueba ilícita, cit. nota n ${ }^{\circ} 27$, p. 22 y 77 y ss. En la jurispruencia, Corte Suprema, ingreso Nr. 2333-10 (Cons. 6º).

${ }^{35}$ CERDA, Rodrigo, "La prueba ilícita y la regla de exclusión", Revista de la justicia penal, $\mathrm{N}^{\circ} 6$ (2010), pp. 99-176, p. 159; DIAZ, Luis, "Derechos fundamentales y prueba ilícita en el nuevo proceso penal chileno", en: COLOMA, Rodrigo (Coord.), La prueba en el nuevo proceso penal oral, Santiago: Lexis Nexis, 2003, pp. 129-160, pp. 158 s.; HERNANDEZ, Exclusión de la prueba ilícita, cit. nota n 27, pp. 78 ss.; HORVITZ, María Inés; LOPEZ, Julián, Derecho procesal penal, Tomo II, Santiago: Jurídica de Chile, 2004, pp. 220 y ss.; PINO, Octavio Alejandro, "Teoría de los efectos reflejos de la prueba ilícita o "teoría de los frutos del árbol envenenado"', GJ (2011), pp. 26-37, p. 34; TAVOLARI, Raúl, Instituciones del nuevo proceso penal, Santiago: Editorial Jurídica de Chile, 2007, p. 141.

${ }^{36}$ Corte Suprema, ingreso Nr. 2333-10 (Cons. $6^{\circ}$ ss.); 1741-10 (Cons. 23); 2521-08 (Cons. $8^{\circ}$ ); 5435-07 (Cons. $7^{\circ}$.
} 


\section{Polít. Crim. Vol. 14, No 28 (Diciembre 2019), Art. 5, pp. 186-214. [http://politcrim.com/wp-content/uploads/2019/11/Vol14N28A5.pdf]}

de la fuente independiente, la cual autoriza al tribunal a valorar aquella prueba cuestionada (Cons. $7^{\circ}$,

“(...) los argumentos vertidos por el impugnante confunden dos situaciones disímiles, pues no se ha dado valor a una prueba ilegal, por el contrario, dicha prueba se valoró en forma positiva, precisamente, porque no derivaba de ninguna otra obtenida con infracción de garantías constitucionales ni surgió producto de un procedimiento viciado. Se trata, en consecuencia, de lo que en doctrina se denomina la fuente independiente, esto es, de una vía distinta de admisión de convicción por parte del tribunal, de aquella que se considera ilícita. Dicha autonomía importa en este caso la existencia de prueba anterior y autónoma que permitió acreditar la existencia del ilícito pesquisado y la participación del imputado en él. En conclusión, no se da una relación causal concreta y determinada entre la ilicitud de base y el material probatorio que se pretende excluir (Héctor Hernández Basualto, cit. pp. 22, 77 y 78)”.

Anteriormente, en sentencia ingreso Nr. 5435-07 (Cons. $7^{\circ}$ ) sostenía el máximo tribunal que un medio de prueba no puede ser excluido cuando provenga de una fuente independiente, pues no podrá considerarse como resultado de una infracción de ley,

“(...) no puede ser excluida como prueba ilícita, aquélla que tiene su origen en una fuente independiente de la ilicitud inicial, simplemente, porque en ese caso la referida prueba no sería un "fruto" de la ilicitud (...)"

Por último, la Corte Suprema ha resuelto -sentencia ingreso Nr. 2521-08 (Cons. $8^{\circ}$ y s.)que la afirmación del defensor de encontrarse la sentencia condenatoria fundada en prueba susceptible de ser excluida en atención a su origen, puede ser desmentida bajo el supuesto de que no existe contaminación alguna o antijuridicidad de la prueba, pues ésta no se encuentra causalmente vinculada a la detención declarada ilegal,

“(...) al mérito de la prueba rendida por la defensa durante la audiencia respectiva en esta Corte, no puede darse la supuesta contaminación o ilicitud de la prueba que se pretende, toda vez que la misma se originó en una actuación independiente de la detención, como fue el ingreso al domicilio, autorizado por su propietario o encargado, por lo que aquello obtenido por los funcionarios de carabineros sigue siendo válido, ya que se desprendió de elementos independientes del acto declarado ilegal, como fue, únicamente, la detención del imputado. NOVENO: Que en estas condiciones, la prueba constituida por la declaración de los funcionarios policiales y las obtenidas como consecuencia de la entrada y registro al domicilio del acusado, surgen de una fuente autónoma, esto es, una vía distinta de adquisición de prueba, de modo tal que contrariamente a lo sostenido por la recurrente, la ilegalidad de la detención del imputado declarada por el tribunal de garantía en la audiencia correspondiente, no pudo tener el efecto pretendido de viciar de ilicitud la prueba de cargo o incriminatoria aportada por el Ministerio Público y como consecuencia de ello se advierte que la condena del acusado puede sustentarse sin dificultad en aquellos medios obtenidos legítima y autónomamente de las supuestas manifestaciones irregulares".

Como consecuencia de ello, sostuvo finalmente el máximo tribunal en dicha oportunidad $\left(\right.$ Cons. $12^{\circ}$ ) que toda la prueba incriminatoria provendría de una fuente independiente, ajena a la detención declarada ilegal, 
"Que como corolario de lo anterior, puede afirmarse que toda la prueba de cargo surge de una fuente independiente, corresponde a un cauce investigativo diferente y del todo desligado de la ilegal detención, donde el proceder policial se ajustó a la legalidad vigente, esto es, como manda el artículo 205 del Código Procesal Penal, mediante el ingreso al inmueble donde se presumía se encontraba el imputado con el consentimiento expreso del propietario, obteniendo la evidencia de manos de ese tercero, quien voluntariamente hizo entrega de ella."

\section{Conclusiones preliminares}

Lo sostenido hasta ahora, permite constatar -en los tres sistemas jurídicos analizados- la necesidad de vincular causalmente la infracción a una regla de obtención probatoria con la obtención de un medio de prueba cuestionado, como requisito necesario e ineludible para dar - a priori- lugar a la exclusión de prueba, admitir sus efectos reflejos, o bien aceptar una prohibición probatoria.

Así, la ausencia de dicho vínculo en un caso concreto, más que configurar una excepción a la aplicación de la regla de exclusión o prohibición de valoración probatoria, dará cuenta de la imposibilidad de constituir un presupuesto base para su procedencia.

A continuación, se buscará determinar y precisar cuáles son los criterios materiales que permitirán al juez acreditar o descartar la conexión de causalidad.

\section{La teoría de la equivalencia de las condiciones como criterio para determinar la existencia o inexistencia de un vínculo de causalidad}

Si aceptamos como válida la premisa hasta ahora esgrimida, de acuerdo a la cual la presencia de una relación de causalidad resulta determinante para dar lugar a la exclusión o residualmente, a una prohibición de valoración de prueba, resulta pertinente discutir bajo qué parámetros puede sostenerse válidamente que una acción constituye "la causa de una obtención probatoria". O mejor dicho, corresponde ahora analizar los criterios materiales que permiten tener dicho vínculo por acreditado.

En el derecho penal sustantivo, la constatación de la relación de causalidad entre una acción y un resultado típico se analiza -de acuerdo a la doctrina mayoritaria- ${ }^{37}$ de conformidad a la teoría de la equivalencia de las condiciones. Dicha doctrina sostiene que cada acción (condición) constituye la causa de un resultado, cuando esta no pueda ser suprimida sin que el resultado concreto desaparezca. Así, cada condición en cuya ausencia el resultado no se hubiese producido (condictio sine qua non), será causa de un resultado típico, jurídicopenalmente relevante.

Ahora bien, la relevancia dogmática que desempeña la fórmula de la conditcio sine qua non no se limita al derecho penal sustantivo. Por el contrario, en el marco de la exclusión

37 Por todos, ROXIN, Claus, Strafrecht: allgemeiner Teil Bd. 1 Grundlagen: der Aufbau der Verbrechenslehre, 4. Ed., München: Beck, 2006, A § 11, número al márgen 6. 


\section{Polít. Crim. Vol. 14, № 28 (Diciembre 2019), Art. 5, pp. 186-214. [http://politcrim.com/wp-content/uploads/2019/11/Vol14N28A5.pdf]}

probatoria, para la doctrina y jurisprudencia mayoritaria de los sistemas comparados que se analizan en este trabajo, la respuesta a la pregunta planteada al comienzo de este acápite puede igualmente resolverse por medio de la teoría de la equivalencia de las condiciones.

Como ha sostenido la doctrina mayoritaria en el derecho alemán, ${ }^{38}$ resulta pertinente analizar el problema de la determinación de la relación causal, tanto de la prueba directamente vinculada con la ilicitud como también de aquella derivada ${ }^{39}$, empleando la fórmula de la condictio sine qua non. Al respecto, se considera que dicha herramienta permite válidamente distinguir aquellas acciones que constituyen la causa de una obtención probatoria de aquellas que no lo son, determinando a partir de ello la legalidad de un resultado probatorio jurídicamente relevante. Este mecanismo constituye una herramienta que, pese a las innegables limitaciones que genera la supresión mental hipotética como método de constatación de un vínculo causal, permite disminuir las incertidumbres que la prueba de la causalidad pudiese ofrecer. ${ }^{40}$

La aplicación de esta teoría en el ámbito procesal penal, se efectúa por medio de una operación mental en la cual se suprime la ilicitud cometida durante la recopilación de prueba y se determina -acto seguido- la subsistencia o bien la eliminación del resultado probatorio efectivamente producido. Cuando a pesar de la supresión mental del acto ilegal, el medio de prueba hubiese sido igualmente obtenido en el mismo momento y condiciones en el que efectivamente lo fue, podrá concluirse que la infracción a reglas procesales no se encuentra causalmente vinculada con la obtención de uno o más medios de prueba. ${ }^{41}$ En estos casos, al resultar concluyente que el medio de prueba cuestionado no se encuentra contaminado con la ilicitud, no existirá justificación alguna para impedir la inclusión o valoración probatoria.

\footnotetext{
${ }^{38}$ Cfr. FEZER, Gerhard, “Anmerkung zum Urteil des BGH vom 17.11.1989 - 2 StR 418/89“, JR (1991), pp. 85-88, p. 87; FEZER, Gerhard, "Anmerkung zum Urteil des BGH vom 28.04.1987 - 5 StR 666/86 (LG Hannover)“, JZ (1987), pp. 937-939, p. 939; GODENZI, Grunhild, Private Beweisbeschaffung im Strafprozess, Zürich y otros: Schulthess, 2008, p. 270; KELNHOFER, Hypothetische Ermittlungsverläufe, cit. nota $\mathrm{n}^{\circ}$ 19, p. 100, nota al pie 72; KNOLL, Dieter, Die Fernwirkungen von Beweisverwertungsverboten, Augsburg: AV-Verl., 1992, p. 107; PITSCH, Strafprozessuale Beweisverbote, cit. nota $\mathrm{n}^{\circ}$ 10, p. 89; SCHRÖDER, Beweisverwertungsverbote und Hypothese, cit. nota ${ }^{\circ}$ 19, p. 77.

${ }^{39}$ De acuerdo al nuevo $\S 141$ inc. 4 de la Ordenanza Procesal Penal Suiza "(...) si una prueba que de acuerdo al inciso segundo no pueda valorarse permite la obtención de otro medio de prueba, tampoco puede ésta ser valorada en aquellos casos en los cuales ésta no podría haber sido obtenida de no mediar la obtención de prueba precedente." Un efecto reflejo de la prohibición de valoración probatoria deberá ser admitido entonces, en aquellos casos en los cuales la prueba primaria constituye una condictio-sine-qua-non de la obtención probatoria posterior. Al respecto, WOHLERS, Wolfgang, "Fernwirkung - zur normativen Begrenzung der sachlichen Reichweite von Verwertungsverboten“, en: ZÖLLER, Mark A.; HILGER, Hans; KÜPER, Wilfried; ROXIN, Claus (Ed.), Gesamte Strafrechtswissenschaft in internationaler Dimension: Festschrift für Jürgen Wolter zum 70. Geburtstag am 7. September 2013, Berlin: Duncker \& Humblot, 2013, pp. 1181-1204, pp. 1193 y ss.

${ }^{40}$ En este sentido la crítica de KLEINKNECHT, Theodor, "Die Beweisverbote im Strafprozeß", NJW (1966), pp. 1537-1545, p. 1544, de acuerdo a la cual la prueba de la causalidad sería "difícil o derechamente imposible“, resulta incorrecta. Vid. REINECKE, Die Fernwirkung von Beweisverwertungsverboten, cit. nota $\mathrm{n}^{\circ}$ 19, p. 57 ss. Escéptico respecto de la prueba de la relación causal también, BGHSt 32, 68 (71).

${ }^{41}$ Cfr. SCHLÜCHTER, Ellen, "Anmerkung zum Urteil des BGH vom 24.8.1983 - 3 StR 136/83 (BGHSt. 32, $68)$ “, $J R$ (1984), pp. 517-522, pp. 519 y 522.
} 


\section{Polít. Crim. Vol. 14, No 28 (Diciembre 2019), Art. 5, pp. 186-214. [http://politcrim.com/wp-content/uploads/2019/11/Vol14N28A5.pdf]}

En el derecho estadounidense el panorama es similar. En algunas de sus decisiones, la Corte Suprema ha afirmado que los resultados del test de supresión mental hipotética resultan decisivos respecto de la decisión final sobre la exclusión o inclusión en juicio de un medio de prueba cuestionado. ${ }^{42}$ En este sentido afirmó dicho tribunal en Segura $v$. United States, ${ }^{43}$ que,

"este caso muestra claramente que la evidencia (cuestionada) no debe ser excluida como "fruto" (del árbol envenenado) a menos que la ilegalidad sea condición sine qua non del descubrimiento de la evidencia".

La aceptación de la suficiencia de la fórmula enunciada como criterio exclusivo para dar lugar a la exclusión probatoria debe sin embargo ser matizada. Ya en Wong Sung v. U.S. ${ }^{44}$ sostenía la Corte Suprema que no resulta posible sostener que toda la evidencia obtenida debe ser excluida, simplemente porque esta no hubiese podido ser obtenida de no ser por las actividades ilícitas cometidas por la policía. En este sentido, más recientemente la Corte Suprema ha sostenido en Hudson v. Michigan ${ }^{45}$ que la fórmula sine qua non debe ser considerada como "necesaria aunque no suficiente"46 como presupuesto de una exclusión probatoria. $^{47}$

El mencionado reconocimiento de parte de la Corte Suprema estadounidense de la insuficiencia de la equivalencia de las condiciones como fenómeno desencadenante (de manera automática) de una exclusión probatoria, se vincula estrechamente con el progresivo desarrollo alcanzado por la regla de exclusión, como una teoría cuyos contornos y alcance comprenden un análisis global de diversos intereses contrapuestos vinculados al caso concreto. ${ }^{48}$ La exclusión mecánica de todo medio de prueba causalmente relacionado con una infracción cometida por personal policial al realizar una diligencia investigativa resultaría desproporcionada, y deberá por ello ser necesariamente confrontada con otros parámetros, como lo es paradigmáticamente el interés de la sociedad en la sanción de las

\footnotetext{
${ }^{42}$ Vid. AMBOS, Beweisverwertungsverbote, cit. nota ${ }^{\circ} 10$, p. 140.

43 "Our case make clear that evidence will not be excluded as "fruit" unless the illegality is at least the "butfor" cause of the discovery of the evidence", Segura v. U.S., 468 U.S. 796, 815 (1984).

${ }^{44}$ Wong Sun v. U.S., 371 U.S. 471, 487, 488 (1963), "(w)e need not hold that all evidence is "fruit of the poisonous tree" simply because it would not have come to light but for the illegal actions of the police."Vid. COMMENT, "Fruit of the Poisonous Tree. A Plea for Relevant Criteria", U. Pa. L. Rev., Vol. 115, Nr. 7 (1967), pp. 1136-1153, p. 1143.

${ }^{45}$ Hudson v. Michigan, 547 U.S. 583, 592 (2006). Vid. ALSCHULER, Albert W., "The Exclusionary Rule and Causation: Hudson v. Michigan and its ancestors", Iowa L. Rev., Vol. 93, N 5 (Julio 2008), pp. 17411817, p. 1743; AMBOS, Beweisverwertungsverbote, cit. nota $\mathrm{n}^{\circ}$ 10, p. $140 \mathrm{~s}$. Ver también, ISRAEL, Jerold H.; KAMISAR, Yale; KERR, Orin S.; KING, Nancy J.; LAFAVE, Wayne R., Modern criminal procedure: cases, comments, and questions, 12a Ed., St. Paul, MN: Thomson West, 2008, pp. 900 ss.

46 "Exclusion may not be premised on the mere fact that a constitutional violation was a "but-for" cause of obtaining evidence. Our cases show that but-for causality is only a necessary, not a sufficient, condition for suppression".

47 Cfr. ALSCHULER, "The Exclusionary Rule and Causation", cit. nota n’ 45, p. 1803; AMBOS, Beweisverwertungsverbote, cit. nota $\mathrm{n}^{\circ} 10$, p. $140 \mathrm{~s}$.

${ }^{48}$ Vid. además, AMBOS, Beweisverwertungsverbote, cit. nota $n^{\circ} 10$, p. 141.
} 


\section{Polít. Crim. Vol. 14, No 28 (Diciembre 2019), Art. 5, pp. 186-214. [http://politcrim.com/wp-content/uploads/2019/11/Vol14N28A5.pdf]}

conductas constitutivas de delito. ${ }^{49}$ Lo anterior permite explicar la existencia de las conocidas excepciones a la regla de exclusión reconocidas por el derecho estadounidense ${ }^{50}$, que posibilitan la admisión un medio de prueba en juicio, a pesar de la innegable constatación de una relación de causalidad.

En contra de la condictio sine qua non como mecanismo idóneo de selección de cursos causales en materia de exclusión de prueba, Alschuler ${ }^{51}$ ha propuesto su reemplazo por el concepto normativo de "causa contributiva" (contributory causation). De acuerdo a esta postura, el tribunal no debiese determinar si la lesión a una garantía constitucional en los hechos permitió una obtención probatoria, sino si la infracción simplificó el descubrimiento y obtención de la prueba. Para sustentar su afirmación cita el ya mencionado caso Hudson v. Michigan, oportunidad en la cual se discutió la legalidad de prueba obtenida mediante un allanamiento llevado a cabo sin que la policía efectuara el debido anuncio previo (" $k n o c k$ and announce requirement"), requisito necesario en el derecho estadounidense para llevar a cabo un ingreso en el marco de un procedimiento policial. El análisis de dicha omisión condujo - de acuerdo al tribunal de fondo- a desestimar la solicitud de exclusión de la prueba cuestionada, pues la falta de anuncio de parte de la policía no resultó causalmente vinculada a la obtención probatoria en el sentido de una causa sine qua non: en caso que la policía se hubiese anunciado debidamente como paso previo a la entrada, igualmente se hubiesen incautado los documentos cuestionados. Al respecto, sostuvo el referido autor que si bien la inobservancia de las reglas de aviso previo al ingreso no resulta una causa sine qua non de la obtención de un medio de prueba, la infracción de garantías constitucionales ha simplificado en este caso la obtención probatoria, razón por la cual la exclusión del medio de prueba debiese ser contestada de manera afirmativa.

Dicha posición no resulta convincente. En efecto, la exclusión probatoria en los EE.UU. justifica la exclusión de prueba estrictamente vinculada a una infracción de garantías. Si la finalidad buscada con dicha regla es la disuasión policial, y finalmente, el resguardo de garantías vulneradas, resulta lógico sancionar con la exclusión únicamente aquellos medios de prueba originados como consecuencia de dicha infracción. Excluir medios de prueba no relacionados causalmente de manera directa con una infracción de garantías impedirá dotar de la suficiente legitimidad a dicha decisión, privando sin suficiente justificación al Estado de medios de prueba que pudiesen resultar determinantes para establecer la culpabilidad de un imputado.

\footnotetext{
${ }^{49}$ Cfr. ISRAEL, Jerold H.; KAMISAR, Yale; LAFAVE, Wayne R., Criminal procedure and the constitution, leading Supreme Court cases and introductory text. 1995 Edition. American Casebook Series, St.Paul, Minn: West Group, 1995, p. 510.

${ }^{50}$ Fundamentalmente, nos referimos a la excepción del vínculo atenuado ("purged taint exception", también conocida como "attenuated connection exception"), originalmente concebida en Nardone v. U.S., 308 U.S. 338 (1939) y décadas después delimitada y precisada en Wong Sun v. U.S., 371 U.S. 471 (1963); la excepción del descubrimiento inevitable ("inevitable discovery exception") delineada fundamentalmente en Nix $v$. Williams, 467 U.S. 431 (1984) y la controvertida excepción de buena fe del agente ("good faith exception") reconocida en U.S. v. Leon, 468 U.S. 897 (1984). Vid. CORREA, "La buena fe del agente” cit. nota $n^{\circ} 3$, pp. y 26 ss.

${ }^{51}$ ALSCHULER, "The Exclusionary Rule and Causation", cit. nota n 45, p. 1745.
} 


\section{Polít. Crim. Vol. 14, No 28 (Diciembre 2019), Art. 5, pp. 186-214. [http://politcrim.com/wp-content/uploads/2019/11/Vol14N28A5.pdf]}

Por las razones expuestas, para la comprobación del vínculo causal en el derecho chileno resulta igualmente necesario aplicar la fórmula de la condictio sine qua non: si suprimida mentalmente la infracción de garantías, la prueba cuestionada no hubiese sido obtenida de la misma forma y en el mismo estado en que efectivamente se recabó, podrá concluirse que la infracción cometida se encuentra causalmente vinculada a la obtención de un medio de prueba. Cuando por el contrario, producto de dicha supresión mental el medio probatorio cuestionado hubiese podido igualmente ser recabado, se rechazará una conexión causal impidiendo la exclusión o prohibición de valoración de este.

\section{El problema de la llamada "causalidad alternativa" y su tratamiento procesal}

Si bien la existencia o inexistencia de un vínculo de causalidad constituye un elemento esencial al momento de resolver acerca de la licitud de la prueba cuestionada, resulta pertinente analizar si lo sostenido hasta ahora recibe aplicación en aquellos supuestos vinculados a la denominada causalidad alternativa.

En estos casos, discutidos principalmente en el derecho penal sustantivo, ${ }^{52}$ resulta posible constatar la presencia de dos cursos causales independientes el uno del otro, coincidentes temporalmente entre sí, y respecto de los cuales cada uno de ellos, por sí sólo -con independencia del otro- conduce un determinado resultado típico. Para dar solución a estos casos, se ha sostenido que resulta necesario modificar la teoría de la equivalencia de las condiciones, aplicando el referido ejercicio de la supresión mental hipotética ya no respecto de un único curso causal, sino de ambos, alternativamente y por separado. De este modo, cuando varias condiciones puedan ser suprimidas mentalmente de modo alternativo pero no cumulativo, sin que desaparezca el resultado, cada una de ellas será causante del resultado típico. ${ }^{53}$

En materia probatoria, dicho fenómeno se aprecia en aquellos casos en los cuales dos o más actuaciones de la investigación se encuentran vinculadas con la obtención de un medio de prueba. Si cada diligencia investigativa puede ser individualmente más no cumulativamente suprimida sin desaparecer el medio de prueba cuestionado, será cada una de ellas causante de la obtención probatoria. A este respecto es posible apreciar tres grupos de casos.

En primer lugar, podría suceder que ninguno de los cursos causales efectivamente vinculados a la obtención de un medio de prueba sea ilícito. Siendo todos los cursos causales reconducibles a actuaciones conforme a derecho, cualquier pérdida de eficacia de la prueba así obtenida deberá ser descartada.

Cuando por el contrario, diversos cursos causales alternativos se encuentren causalmente vinculados a una infracción de garantías, no resultará posible reconducir la obtención

\footnotetext{
${ }^{52}$ Vid. BEULKE, Werner; SATZGER, Helmut; WESSELS, Johannes, Strafrecht Allgemeiner Teil: Die Straftat und ihr Aufbau: Lehrbuch, Entscheidungen, Gesetzestexte, 45. Ed., Heidelberg y otros: Müller, 2015, número al margen 222.

53 BEULKE, Werner; SATZGER, Helmut; WESSELS, Johannes, Strafrecht..., cit. nota ${ }^{\circ} 52$, número al margen 222.
} 


\section{Polít. Crim. Vol. 14, № 28 (Diciembre 2019), Art. 5, pp. 186-214. [http://politcrim.com/wp-content/uploads/2019/11/Vol14N28A5.pdf]}

probatoria cuestionada a un camino lícito. De este modo, la prueba cuestionada deberá ser indudablemente- excluida o respectivamente, no valorada.

Como tercera posibilidad, puede acaecer que tan sólo uno de los cursos causales alternativos que condujo a la obtención de la prueba cuestionada se encuentre contaminado con la ilicitud. En estos casos se presentan distintos caminos que conducen, alternativamente, a la obtención de un medio de prueba, siendo alguno(s) de ellos reconducible a una ilicitud y el(los) otro(s) a una actuación conforme a derecho. Como ha sostenido acertadamente parte importante de la doctrina alemana, ${ }^{54}$ si resulta posible reconducir la obtención del medio de prueba cuestionado a lo menos a un curso causal jurídicamente irreprochable, será posible aceptar la valoración del medio de prueba cuestionado.

En el derecho chileno resulta correcto admitir la inclusión o respectivamente la valoración de un determinado medio de prueba obtenido tanto por medio de un suceso causal antijurídico, como por otro realizado conforme a derecho. Dado que en estos casos el origen del medio de prueba cuestionado resulta susceptible de ser reconducido en último término a una fuente no contaminada, primará la correcta averiguación de la verdad como finalidad procesal. La resolución que se dicte incluyendo o valorando el medio de prueba cuestionado podrá en su fundamentación prescindir del curso causal contrario a derecho, reconduciendo la obtención cuestionada exclusivamente a un camino lícito.

\section{Algunos lineamientos para la simplificación de la prueba de la relación causal}

La prueba de la relación de causalidad constituye, como se ha señalado, una tarea ineludible para el tribunal al momento de resolver cuestiones referidas a la exclusión o prohibición de valoración de prueba y que debe ser resuelta caso a caso. ${ }^{55}$

Ahora bien, para determinar la existencia o inexistencia de una relación de causalidad entre una diligencia probatoria contraria a derecho y la obtención de un determinado medio de prueba, confluyen problemas de diversa índole entre los que se cuentan, sobre todo, dificultades probatorias. Estas imposibilitan muchas veces la determinación del momento exacto y las condiciones en las que se produjo la obtención probatoria cuestionada,

\footnotetext{
${ }^{54}$ AMBOS, Beweisverwertungsverbote, cit. nota ${ }^{\circ} 10$, p. 149; DENCKER, Friedrich, Verwertungsverbote im Strafprozeß: ein Beitrag zur Lehre von den Beweisverboten, Köln; München y otros: Heymann, 1977, p. 80; GUNDLACH, Rainer, "§136a“, en: WASSERMANN, Rudolf (Ed.), Kommentar zur Strafprozessordnung in der Reihe Alternativkommentare, Tomo II/l. Neuwied: Luchterhand, 1992, número de párrafo 82; JÄGER, Christian, "Beweiserhebungs- und Beweisverwertungsverbote als prozessuale Regelungsinstrumente im strafverfolgenden Rechtsstaat. Zugleich ein Beitrag zum 67. Deutschen Juristentag", GA t. 155 (2008), pp. 473-499, p. 494; ROGALL, "§136a“, cit. nota n 11, número al margen 116 s.; FEZER, Strafprozeßrecht, cit. nota $\mathrm{n}^{\circ}$ 28, Caso Nr. 16, número al márgen 50; HARRIS, "Verwertungsverbot für mittelbar erlangte Beweismittel" cit. nota $\mathrm{n}^{\circ} 10$, p. 319; PAULUS, Rainer, "Rechtsdogmatische Bemerkungen zum Urkundenbeweis in der Hauptverhandlung des Strafverfahrens", JuS t. 28 (1998), pp. 873-879, p. 876; REICHERT-HAMMER, Hansjörg, "Zur Fernwirkung von Beweisverwertungsverboten (§136a StPO) BHGSt 34, 362“, JuS (1989), pp. 446-450, p. 450; SCHLÜCHTER, "Anmerkung zum Urteil“, cit. nota n 41, p. 519; WOLTER, Jürgen, “Anmerkung zum Urteil des BGH vom 24.08.1983 NStZ 1984, 275 ff.”, NStZ t. 6 (1984), pp. 276-278, p. 277.

${ }^{55}$ En la jurisprudencia alemana, BGHSt 29, 244 (252).
} 


\section{Polít. Crim. Vol. 14, № 28 (Diciembre 2019), Art. 5, pp. 186-214. [http://politcrim.com/wp-content/uploads/2019/11/Vol14N28A5.pdf]}

impidiendo ello constatar a ciencia cierta la pretendida "contaminación" del medio de prueba cuestionado.

Para simplificar dicha tarea resulta especialmente relevante considerar los lineamientos esgrimidos por el derecho alemán y estadounidense al resolver respecto de la llamada excepción de la fuente independiente, muchos de los cuales -como veremos- han sido recogidos por nuestros tribunales superiores.

En primer lugar, resulta necesario hacer referencia a criterios de índole temporal. Así, en aquellos casos en los cuales se acredite que el medio de prueba cuestionado fue obtenido con anterioridad al acto probatorio contrario a derecho, ${ }^{56}$ resultará lógico concluir que este no se encuentra contaminado con la ilicitud. ${ }^{57}$ Atendido que en estos casos el medio de prueba fue obtenido de manera previa a la realización de la conducta antijurídica, la obtención del medio de prueba cuestionado no podrá ser -en caso alguno- reconducida a una actuación ilícita: ${ }^{58}$ se trata entonces de una obtención probatoria que proviene de una verdadera fuente independiente. ${ }^{59}$

Por el contrario, si se acredita que los funcionarios obtuvieron el medio de prueba cuestionado después de la diligencia investigativa antijurídica, la determinación de la licitud de la obtención resulta especialmente compleja ${ }^{60}$ En estos casos, deberá el tribunal determinar si el medio de prueba cuestionado fue o no obtenido con independencia de la diligencia investigativa contraria a derecho. Para ello, tendrá que considerar una serie de criterios fácticos, entre los cuales resulta especialmente relevante el conocimiento de la ilicitud cometida que haya tenido el funcionario a cargo del procedimiento al momento de la obtención probatoria. Si el policía, al conseguir el medio de prueba cuestionado, no tenía conocimiento alguno de una actuación contraria a derecho cometida anteriormente, resulta posible inferir que la obtención probatoria pueda válidamente ser considerada conforme a derecho, posibilitando la inclusión del medio de prueba cuestionado. ${ }^{61} \mathrm{~A}$ contrario sensu, $\mathrm{si}$ el funcionario a cargo de la obtención participó, o bien conocía de la actuación antijurídica al momento de practicar la diligencia que condujo a la prueba cuestionada, constituirá ello un indicio a favor de la vinculación causal entre ambas acciones.

\footnotetext{
${ }^{56}$ Cfr. AMBOS, Beweisverwertungsverbote, cit. nota $n^{\circ}$ 10, p. 132; PITLER, "The Fruit of the poisonous Tree", cit. nota $\mathrm{n}^{\circ} 12$, p. 626.

${ }^{57}$ Cfr. AMBOS, Beweisverwertungsverbote, cit. nota $\mathrm{n}^{\circ}$ 10, p. 132; HARRIS, "Verwertungsverbot für mittelbar erlangte Beweismittel", cit. nota ${ }^{\circ}$ 10, p. 316; PITSCH, Strafprozessuale Beweisverbote, cit. nota $\mathrm{n}^{\circ}$ 13, p. 400 s. En la jurisprudencia: Burke v. U.S., 328 F. 2d 399 (1st Cir. 1964); U.S. v. Lee, 274 U.S. 559, 563 (1927).

${ }^{58}$ Cfr. BVerfG decisión del 8 de diciembre 2005, 2BvR 1686/04, número al margen 10.

${ }^{59}$ Eso sucede por ejemplo en Bynum v. U.S., 262 F. 2d 465, 468, 469 (D.C. Cir. 1958) y Commonwealth v. Nicholls, 207 Pa. Super. 410, 217 A.2d 768 (1966). En la jurisprudencia chilena, Corte Suprema ingreso Nr. 49.714-2016, Cons. $5^{\circ}$. En la doctrina chilena, HERNANDEZ, Exclusión de la prueba ilícita, cit. nota n ${ }^{\circ} 27$, p. 22.

${ }^{60}$ Cfr. AMBOS, Beweisverwertungsverbote, cit. nota ${ }^{\circ} 10$, p. 132. En la jurisprudencia chilena, Corte Suprema ingreso Nr. 49.714-2016, Cons. 5. En la doctrina chilena, HERNANDEZ, Exclusión de la prueba ilícita, cit. nota $\mathrm{n}^{\circ} 34$, p. 22.

${ }^{61}$ Cfr. AMBOS, Beweisverwertungsverbote, cit. nota $\mathrm{n}^{\circ}$ 10, p. 132; HARRIS, "Verwertungsverbot für mittelbar erlangte Beweismittel" cit. nota ${ }^{\circ}$ 10, p. 316. En la jurisprudencia, U.S. v. Bacall, 443 F. 2d 1050, 1057 (9th Cir. 1971); Segura v. U.S., 468 U.S. 796 (1984).
} 
Por otro lado, para la acreditación de la relación causal en aquellas situaciones en las cuales la expedición de una orden o autorización emanada de un tribunal constituye un presupuesto necesario para la obtención de prueba, cobra especial relevancia la pregunta acerca de la legalidad de los argumentos y elementos probatorios previamente invocados por los solicitantes al tribunal, y que permitieron la dictación de la autorización que finalmente condujo a la prueba.

A este respecto, podrá rechazarse la vinculación de un medio de prueba con una actuación contraria a derecho cuando la decisión del órgano adjudicador que permitió su obtención fue adoptada en base a antecedentes provenientes de actuaciones lícitas. Cuando por el contrario, la resolución del juez se fundamente en circunstancias vinculadas a actuaciones de investigación atentatorias de garantías, podrá considerarse que la autorización expedida se encuentra igualmente contaminada con la ilicitud previa, y con ello también la prueba resultante de dicha permisión lo estará. Este será el caso, por ejemplo, en el cual tras ingresar la policía -sin contar con la debida orden- a un domicilio, incauta una libreta con anotaciones que permiten vincular a distintos sujetos en la comisión del delito y a partir de dichos registros se solicita posteriormente al fiscal autorización para interceptar los teléfonos de quienes allí se señalan. En caso de que la respectiva autorización finalmente sea concedida podrá concluirse que los elementos probatorios obtenidos gracias a la interceptación (indebidamente) autorizada se encontrarán causalmente vinculados con una actuación contraria a derecho y por lo tanto serán susceptibles de ser excluidos y/o de no ser valorados por parte de un tribunal penal.

La Corte Suprema estadounidense ha debido pronunciarse en a lo menos dos oportunidades respecto de este último punto. En Segura v. United States ${ }^{62}$ se discutió respecto de la licitud de la evidencia incautada por la policía desde el domicilio del imputado, obtenida -a juicio de la defensa- sin contar con la necesaria orden de ingreso y registro. En este caso, tras haber practicado una serie de detenciones vinculadas a una red de tráfico de cocaína, ingresó la policía de manera ilegal al domicilio del imputado, antes de obtener la orden de ingreso ya solicitada. En dicha oportunidad, los agentes observan en el interior del recinto la presencia de elementos probatorios vinculados al tráfico de drogas, los cuales finalmente no incautan. Tras ello, deciden los funcionarios abandonar la morada permaneciendo en las cercanías del recinto, esperando la necesaria orden de ingreso y registro de parte del juez. Finalmente, premunidos ya de la debida orden, ingresan una vez más al domicilio, oportunidad en la que incautan entre otros elementos cocaína y parafernalia relacionada con la producción de sustancias prohibidas.

Al pronunciarse la Corte Suprema respecto de la licitud de los elementos obtenidos desde el domicilio del recurrente, concluyó que el descubrimiento e incautación de los medios de prueba tuvo su origen en una autorización judicial de ingreso a un lugar cerrado que no se encuentra de modo alguno relacionada con el ingreso ilegal, al haber sido solicitada con anterioridad a este. A partir de ello, determinó la Corte que la ilicitud efectivamente

${ }^{62}$ Segura v. U.S., 468 U.S. 796 (1984). 


\section{Polít. Crim. Vol. 14, № 28 (Diciembre 2019), Art. 5, pp. 186-214. [http://politcrim.com/wp-content/uploads/2019/11/Vol14N28A5.pdf]}

cometida no incidió de forma alguna respecto de la legalidad de la posterior incautación del material probatorio, rechazando de este modo la exclusión solicitada. ${ }^{63}$

Producto de información obtenida por informantes anónimos, en Murray v. United States ${ }^{64}$ el imputado fue sometido a vigilancia por parte de la policía. Posteriormente, tras recopilar diversas fuentes de información, las operaciones de la policía se centraron en la localización de un depósito sospechoso, lugar al cual la policía ingresó de manera violenta y sin contar con la necesaria autorización judicial. Dentro del recinto se encontraron un sinnúmero de pequeñas bolas, las cuales -según se determinó posteriormente- contenían drogas. La policía, consciente de la ilegalidad de su actuar, abandonó el depósito sin siquiera tocar los elementos sospechosos, manteniendo a personal vigilando afuera del recinto, y procurando no ingresar nuevamente al lugar mientras no contasen con la debida autorización judicial, la cual proceden a solicitar. Al momento de requerir dicha orden de entrada y registro, los funcionarios no mencionaron al juez el ingreso previo, ni tampoco el hallazgo de las referidas bolas. Expedida ya la orden, ingresan los policías nuevamente al lugar incautando múltiples dosis de marihuana.

Si bien en este caso - a diferencia de Segura- la orden de entrada y registro no fue solicitada temporalmente antes del ingreso ilegal, la autorización judicial fue igualmente obtenida sin recurrir a información relacionada con la actuación contraria a derecho. Producto de ello, resolvió la Corte que la excepción de la fuente independiente no solamente se vincula a elementos probatorios que se descubren por vez primera durante un ingreso conforme a derecho, sino que resulta aplicable incluso respecto de aquellos medios de prueba que durante o con ocasión de un ingreso ilegal sean descubiertos, cuando estos más adelante y de manera independiente a la ilicitud original, sean finalmente obtenidos. ${ }^{65}$

En el derecho chileno la pregunta sobre la licitud de una obtención probatoria debe igualmente considerar la aplicación de criterios cognitivos y temporales para ser adecuadamente resuelta. En relación con esto último, resultará necesario analizar caso a caso si el medio de prueba cuestionado fue obtenido antes o después de la actuación contraria a derecho ${ }^{66}$ En el primer caso, no podría el elemento probatorio impugnado -por razones de lógica temporal- verse afectado por la actuación antijurídica. Cuando en contraposición a ello, el medio de prueba se hubiere obtenido después de realizada la diligencia atentatoria de garantías, la licitud de la obtención podrá acreditarse -por

\footnotetext{
${ }^{63}$ Vid. HARRIS, "Verwertungsverbot für mittelbar erlangte Beweismittel" cit. nota ${ }^{\circ}$ 10, p. 316.

${ }^{64}$ Murray v. U.S., 487 U.S. 533, 539 (1988).

${ }^{65}$ Como sostuvo la Corte Suprema en Murray v. U.S., 487 U.S. 533, 542 (1988) "La pregunta central consiste en determinar si la búsqueda practica con arreglo a una orden de ingreso fue, de hecho, una fuente genuinamente independiente de información y evidencia tangible. Este podría no ser el caso si la decisión de los agentes de obtener una autorización de ingreso fue provocada por lo que observaron durante la primera entrada o bien, si la información obtenida en la primera entrada fue presentada al magistrado y afectó en su decisión de extender la orden." ("The ultimate question, therefore, is whether the search pursuant to warrant was, in fact, a genuinely independent source of the information and tangible evidence at issue here. This would not have been the case if the agents decision to seek the warrant was prompted by what they had seen during the initial entry, or if information obtained during that entry was presented to the Magistrate and affected his decision to issue the warrant. "). Cfr. U.S. v. Moscatiello, 771 F. 2d, 603, 604 (1st. Cir. 1985).

${ }^{66}$ En este sentido, HERNANDEZ, Exclusión de la prueba ilícita, cit. nota n ${ }^{\circ}$ 27, p. 78.
} 


\section{Polít. Crim. Vol. 14, No 28 (Diciembre 2019), Art. 5, pp. 186-214. [http://politcrim.com/wp-content/uploads/2019/11/Vol14N28A5.pdf]}

ejemplo- a partir del desconocimiento del funcionario encargado de la obtención, respecto de la realización de la diligencia jurídicamente reprochable.

En concordancia con algunas de estas directrices, sostuvo la Corte Suprema en sentencia ingreso Rol Nr. 5435-07 (Cons. $7^{\circ}$ ) que los casos más claros de aplicación de la doctrina de la fuente independiente son aquellos en los cuales la prueba fue obtenida con anterioridad a la actuación ilegal, aunque también puede suceder que en estos casos, la prueba haya sido obtenida con posterioridad a la acción antijurídica.

Igualmente, nuestra Corte Suprema ha resuelto en sentencia ingreso Rol Nr. 2838-03 $\left(\right.$ Cons. $15^{\circ}$ ), que la prohibición de valorar una declaración del imputado obtenida mediante infracción de garantías, no incide en la legalidad de otras actuaciones de la investigación llevadas a cabo por policías, en caso que sus pesquisas hayan sido desarrolladas con anterioridad a la declaración impugnada.

Mediante sentencia ingreso Rol Nr. 1741-10 (Cons. $\left.23^{\circ}\right)$ sostuvo la Corte Suprema que si antes de la conducta ilegal se contaba con información o material probatorio irreprochable, el material obtenido no puede ser excluido pues no constituye realmente el resultado de una actuación ilícita. Al respecto concluye el tribunal, citando a Hernández, que en estos casos no existe una relación causal concreta y específica entre la actuación ilícita y el material probatorio. En concreto se sostuvo,

“(...) aún en el evento que la prueba lograda mediante los primeros contactos con Yanina Furlong pudiera ser calificada de ilícita, el conocimiento de los hechos se había obtenido con anterioridad mediante una fuente independiente, como lo era el relato de un informante. Cuando se posee información o material probatorio preexistente al momento de una actuación tachable de ilegal, no procede excluir la prueba obtenida, ya que esta no es un "fruto" de la ilicitud. En este evento no se da una relación causal concreta y determinada entre la ilicitud de base y el material probatorio que se pretende excluir (Hernández, cit., p.p. 22, 77 y 78), cual es en este caso el obtenido el día en que se llevó a cabo la venta de la droga al policía encubierto. La evidencia supuestamente calificable de ilícitamente obtenida sirvió para confirmar sospechas previas y focalizar la investigación en determinadas imputadas, por lo que la ausencia de un nexo causal concreto impide la exclusión de las pruebas legítimamente obtenidas".

En la misma dirección se pronunció el máximo tribunal (sentencia Nr. 14.781-15, Cons. $9^{\circ}$ ) al sostener que el primer reproche que puede formularse en contra de la pretensión de ilegalidad de la prueba obtenida, radica en su supuesto origen en base a actuaciones ilícitas, las cuales realmente tuvieron lugar de manera previa e independiente de la detención ilegal; ellas no pueden entonces, ser consecuencia de la ilicitud o dependientes de ella, ${ }^{67}$

"Que a este respecto, lo primero que debe descartarse es la supuesta ilicitud de pruebas que se originan en hechos lícitos anteriores e independientes de la práctica de la diligencia que se ha declarado ilegal, esto es, que no son consecuencia ni dependen de la misma, como lo son la incorporación y valoración de las declaraciones de los

\footnotetext{
${ }^{67}$ Vid. CORREA, "Comentario de sentencia" cit. nota ${ }^{\circ}$ 3, p. 165.
} 


\section{Polít. Crim. Vol. 14, No 28 (Diciembre 2019), Art. 5, pp. 186-214. [http://politcrim.com/wp-content/uploads/2019/11/Vol14N28A5.pdf]}

testimonios de un rescatista de bomberos, familiares del occiso y de dos testigos de oídas -amigo y ex polola del acusado-, cuyos testimonios en la investigación de autos fueron recabados durante el diligenciamiento de la instrucción particular dada por el fiscal a efectos de indagar el paradero de la víctima cuando fue denunciada su presunta desgracia, con anterioridad a la declaración del adolescente condenado, sin que pueda vislumbrarse actividad policial ilícita alguna en su obtención (...).”

\section{La relación causal y su incidencia en el recurso de nulidad por la causal establecida en el art. 373 letra a) del CPP.}

El artículo 373 letra a) del CPP sanciona con la nulidad del juicio oral, y de la sentencia aquellos casos en los cuales durante el procedimiento o en el pronunciamiento de la sentencia, se hubieren infringido sustancialmente derechos o garantías asegurados por la Constitución o por los tratados internacionales. En lo que a esto respecta, lo hasta aquí expuesto puede incidir tanto en la acreditación o descarte de dicha causal de nulidad, como en el éxito o fracaso del recurso, a partir de lo dispuesto en el artículo 375 del referido cuerpo legal. Analicemos para concluir ambas posibilidades.

En todos sus supuestos, para que un recurso de nulidad interpuesto por la causal anteriormente referida prospere, es necesario que concurran copulativamente dos requisitos. En primer término, y en virtud de lo dispuesto en el mismo art. 373 letra a) CPP, el vicio que se denuncia debe consistir en una infracción "sustancial" de derechos o garantías. Asimismo, de conformidad a lo preceptuado en el art. 375 del citado código, es necesario satisfacer el requisito de trascendencia del vicio, lo que implica de acuerdo a dicha disposición, acreditar que el vicio invocado influye en la parte dispositiva del fallo. ${ }^{68}$

A este respecto, como ha señalado recientemente un autor, ${ }^{69}$ la Corte Suprema ${ }^{70}$ en su jurisprudencia mayoritaria ha confundido erróneamente el requisito de trascendencia del vicio denunciado, con la infracción sustancial del derecho o garantía infringida. En este sentido, la Corte recurrentemente entiende la trascendencia como un elemento que remite a la gravedad o carácter sustancial de la infracción, ${ }^{71}$ diluyendo con ello la distinción fundamental entre ambos conceptos.

En este sentido, resulta correcto distinguir el carácter sustancial de la infracción en tanto elemento que motiva el recurso y que se configura a partir de una afectación al núcleo de la

\footnotetext{
${ }^{68}$ Al respecto, vid. DEL RIO, Carlos, "El principio de trascendencia en relación con el motivo de recurso de nulidad del artículo 373 letra a) del Código Procesal Penal chileno”, Polit. crim. Vol. 13, N²5 (Julio 2018), pp. 322-349; HORVITZ, María Inés; LOPEZ, Julián, Derecho procesal penal, cit. nota 35, pp. 392 y ss.; RIEUTORD, Andrés, El recurso de nulidad en el nuevo proceso penal, Santiago: Ed. Jurídica de Chile, 2007, pp. 42 y ss.

${ }^{69}$ DEL RIO, Carlos, "El principio de trascendencia”, cit. nota ${ }^{\circ} 68$, pp. 332 y ss. Vid. recientemente, Corte Suprema, Ingresos Nr. 556-2014; 5851-2015; 31.025-2016; 76.424-2016.

${ }^{70}$ Vid. recientemente, Corte Suprema, Ingresos Nr. 556-2014; 5851-2015; 31.025-2016; 76.424-2016.

${ }^{71}$ DEL RIO, Carlos, "El principio de trascendencia", cit. nota ${ }^{\circ} 74$, p. 334.
} 


\section{Polít. Crim. Vol. 14, No 28 (Diciembre 2019), Art. 5, pp. 186-214. [http://politcrim.com/wp-content/uploads/2019/11/Vol14N28A5.pdf]}

garantía resguardada ${ }^{72}$ del principio de trascendencia, entendido este como una capacidad o potencialidad del vicio para influir en lo dispositivo del fallo. ${ }^{73}$

Si se acepta la validez de la distinción referida, los distintos problemas tratados a lo largo de este artículo pueden tener incidencia tanto en relación con la configuración misma del vicio de nulidad, como en lo referido al principio de trascendencia, permitiendo ello finalmente distinguir entre infracciones de garantías causalmente vinculadas a una obtención probatoria que efectivamente traerán como consecuencia una declaración de nulidad, de aquellas que no.

En primer término, aquellos recursos de nulidad en los cuales la defensa esgrima una infracción de garantías fundada en una supuesta obtención probatoria ilícita, pero que en realidad se trate de supuestos en los cuales el medio de prueba ha sido obtenido producto de una diligencia llevada a cabo conforme a derecho, deberán ser desestimados. En estos casos, atendida la licitud de la obtención probatoria, no se configurará la causal misma de nulidad referida: el medio de prueba no se encuentra causalmente conectado a infracción alguna de garantías.

Por el contrario, en aquellos casos en los cuales efectivamente resulte posible determinar que el medio de prueba cuestionado ha sido obtenido con infracción de garantías, deberá determinarse si dicha infracción posee el carácter de sustancial, en el sentido esgrimido en el art. 373 letra a) CPP. De este modo, solo en aquellos casos en los cuales la infracción esgrimida sea reconducible a una lesión de entidad vinculada al núcleo de la garantía resguardada, se configurará la causal de nulidad referida.

Sin embargo, como indicamos supra, dicho examen no resulta suficiente para que el recurso de nulidad interpuesto por la defensa sea acogido. En un segundo nivel, vinculado esta vez al art. 375 CPP, resulta necesario determinar si en la especie concurre el requisito de trascendencia que debe acompañar a la infracción alegada. Dicho requisito puede también analizarse a la luz de lo expuesto a lo largo de este trabajo. ${ }^{74}$

En efecto, en aquellos casos en los cuales estemos frente al ya descrito fenómeno de la causalidad alternativa en materia probatoria, la presencia de (a lo menos) un curso causal lícito vinculado a la obtención del medio de prueba cuestionado tendrá incidencia en materia de nulidad. Si como ya se expuso, basta la presencia de a lo menos un curso causal lícito para validar una obtención de prueba cuestionada, aquellas infracciones denunciadas en sede de nulidad que se encuentren en esta situación, carecerán de la necesaria trascendencia.

\footnotetext{
72 Sobre el concepto de núcleo de la garantía, vid. en el derecho alemán, ROGALL, Klaus, "Kernbereichsmystik im Strafverfahren“, en: WESSLAU, Edda; WOHLERS, Wolfgang (Ed.), Festschrift für Gerhard Fezer zum 70. Geburtstag am 29. Oktober 2008, Berlin: De Gruyter, 2008, pp. 61-86.

${ }^{73}$ DEL RIO, Carlos, "El principio de trascendencia", cit. nota n 68 , pp. 334 y ss.

${ }^{74}$ Sin perjuicio de la relevancia de la causalidad en relación con la trascendencia del vicio, resulta igualmente relevante analizar a este respecto si concurre alguna de las excepciones a la exclusión de prueba, tradicionalmente aceptadas por la doctrina y la jurisprudencia chilena, en especial, la doctrina del vínculo atenuado y la doctrina del descubrimiento inevitable.
} 


\section{Polít. Crim. Vol. 14, No 28 (Diciembre 2019), Art. 5, pp. 186-214. [http://politcrim.com/wp-content/uploads/2019/11/Vol14N28A5.pdf]}

En estos casos, la presencia de un curso causal lícito, bastará para concluir que el vicio denunciado constituye un defecto no esencial. Este defecto, si bien susceptible de configurar la hipótesis de nulidad del art. 373 letra a) CPP, no resultará idóneo para influir en lo dispositivo del fallo. El tribunal, ya lo sabemos, podrá recurrir a la obtención lícita para justificar la inclusión y/o la valoración probatoria denunciada.

\section{Conclusiones}

La exclusión de prueba ilícita o bien la aceptación de una prohibición de valoración de prueba, será sólo procedente cuando la obtención probatoria sea reconducible a una actuación contraria a derecho de parte de los funcionarios persecutores.

En caso de que sea posible acreditar la presencia de un curso causal realizado y que haya posibilitado su obtención conforme a derecho, la ilicitud de la prueba cuestionada deberá ser desestimada. A la conclusión anterior no obsta la presencia de uno o más cursos causales ilícitos que igualmente condujeron a idéntico resultado probatorio.

Al momento de resolver sobre la vinculación de un medio de prueba a una actividad de investigación contraria a derecho, el tribunal deberá considerar especialmente si el momento en el cual la prueba cuya ilicitud se atribuye resulta temporalmente anterior o posterior a la actuación ilícita; el conocimiento del funcionario a cargo de la obtención probatoria respecto de la ilicitud de una actuación anterior, e igualmente el origen de los antecedentes esgrimidos ante el juez y considerados por el mismo al momento de autorizar la realización de una determinada diligencia de investigación.

La existencia de una infracción al núcleo de la garantía resguardada, con motivo de la obtención de uno o más elementos probatorios, podrá configurar - previo cumplimiento de los requisitos procesales establecidos al efecto- la causal de nulidad establecida en la letra a) del art. 373 CPP.

Aún en estos casos, independiente de la acreditación del vicio de nulidad, la existencia de un curso causal lícito vinculado a la obtención del medio probatorio cuestionado impedirá acoger el recurso, al no cumplirse con el requisito de trascendencia establecido en el art. 375 del referido cuerpo legal. 


\section{Bibliografía}

ALSCHULER, Albert W., "The Exclusionary Rule and Causation: Hudson v. Michigan and its ancestors", Iowa L. Rev., Vol. 93, N 5 (Julio 2008), pp. 1741-1817.

AMBOS, Kai, Beweisverwertungsverbote: Grundlagen und Kasuistik - internationale Bezüge - ausgewählte Probleme, Berlin: Duncker \& Humblot, 2010.

BEULKE, Werner; SATZGER, Helmut; WESSELS, Johannes, Strafrecht Allgemeiner Teil: Die Straftat und ihr Aufbau: Lehrbuch, Entscheidungen, Gesetzestexte, 45. Ed., Heidelberg y otros: Müller, 2015.

CAROCCA PÉREZ, Alex, "Una primera aproximación al tema de la prueba ilícita en Chile", Ius et Praxis, vol. 4 N 2 (1998), pp. 301-322.

CERDA SAN MARTIN, Rodrigo, "La prueba ilícita y la regla de exclusión”, Revista de la justicia penal, $\mathrm{N}^{\circ} 6$ (2010), pp. 99-176.

COMMENT, "Fruit of the Poisonous Tree. A Plea for Relevant Criteria", U. Pa. L. Rev., Vol. 115, Nr. 7 (1967), pp. 1136-1153.

CORREA ROBLES, Carlos, "La buena fe del agente como excepción a la aplicación de la regla de exclusión -derecho estadounidense y derecho chileno-", Latin American legal Studies, Vol. 2 (2018), pp. 25-50.

CORREA ROBLES, Carlos, "Más allá de la regla de exclusión: prohibiciones probatorias en el Derecho chileno - con especial referencia al Derecho alemán-" Polit. crim., Vol. 13, No 25 (Enero 2018), pp. 144-174

CORREA ROBLES, Carlos, "Comentario de sentencia Corte Suprema ingreso número 14781-2015: efectos reflejos de la prueba obtenida mediante infracción de garantías”, Revista de Ciencias Penales, Sexta Época, Vol. 43, ํㅜ 1 (2016), pp. 159-176.

DENCKER, Friedrich, Verwertungsverbote im Strafprozeß: ein Beitrag zur Lehre von den Beweisverboten, Köln; München y otros: Heymann, 1977.

DEL RIO FERRETTI, Carlos, "El principio de trascendencia en relación con el motivo de recurso de nulidad del artículo 373 letra a) del Código Procesal Penal chileno", Polit. crim., Vol. 13, N²5 (Julio 2018), pp. 322-349.

DIAZ GARCIA, Luis, "Derechos fundamentales y prueba ilícita en el nuevo proceso penal chileno", en: COLOMA CORREA, Rodrigo (Coord.), La prueba en el nuevo proceso penal oral, Santiago: Lexis Nexis, 2003, pp. 129-160.

ECHEVERRIA, Isabel, Los derechos fundamentales y la prueba ilícita: con especial referencia a la prueba ilícita aportada por el querellante particular y por la defensa, Santiago: Eds. Jurídicas de Santiago, 2010.

FEZER, Gerhard, Strafprozeßrecht, $2^{a}$ Ed., München: Juristischer Studienkurs, 1995.

FEZER, Gerhard, “Anmerkung zum Urteil des BGH vom 17.11.1989 - 2 StR 418/89“, JR (1991), pp. 85-88.

FEZER, Gerhard, “Anmerkung zum Urteil des BGH vom 28.04.1987 - 5 StR 666/86 (LG Hannover)“", JZ (1987), pp. 937-939.

GODENZI, Grunhild, Private Beweisbeschaffung im Strafprozess, Zürich y otros: Schulthess, 2008. 
GOLDEN, Troy E., "The Inevitable Discovery Doctrine Today: The Demands of the Fourth Amendment, Nix, and Murray, and the Disagreement Among the Federal Circuits", B.Y.U. Journal of public law, Vol. 13, N 1 (1998), pp. 97-126.

GUNDLACH, Rainer, "§136a", en: WASSERMANN, Rudolf (Ed.), Kommentar zur Strafprozessordnung in der Reihe Alternativkommentare, Tomo II/1. Neuwied: Luchterhand, 1992.

HARRIS, Kenneth, "Verwertungsverbot für mittelbar erlangte Beweismittel: Die Fernwirkungsdoktrin in der Rechtsprechung im deutschen und amerikanischen Recht", StV (1991), pp. 313-322.

HERNANDEZ BASUALTO, Héctor, Exclusión de la prueba ilícita en el nuevo proceso penal chileno, Santiago: Universidad Alberto Hurtado, 2005.

HORVITZ LENNON, María Inés; LOPEZ MASLE, Julián, Derecho procesal penal, Tomo II, Santiago: Jurídica de Chile, 2004.

ISRAEL, Jerold H; KAMISAR, Yale; LAFAVE, Wayne R.. Criminal procedure and the constitution, leading Supreme Court cases and introductory text. 1995 Edition. American Casebook Series, St.Paul, Minn: West Group, 1995

ISRAEL, Jerold H.; KAMISAR, Yale; KERR, Orin S.; KING, Nancy J.; LAFAVE, Wayne R., Modern criminal procedure: cases, comments, and questions, 12a Ed., St. Paul, MN: Thomson West, 2008.

JÄGER, Christian, "Beweiserhebungs- und Beweisverwertungsverbote als prozessuale Regelungsinstrumente im strafverfolgenden Rechtsstaat. Zugleich ein Beitrag zum 67. Deutschen Juristentag", GA t. 155 (2008), pp. 473-499.

JONES, Luther E. Jr., "Fruit of the poisonous tree", S Tex. L. J., Vol. 9 (1967), pp. 17-22.

KELNHOFER, Evelyn, Hypothetische Ermittlungsverläufe im System der Beweisverbote, Berlin: Duncker \& Humblot, 1994.

KILLIAN, Bobbi J., "United States v. Crews: Fruit of the Poisonous Tree - A new wrinkle?", Idaho L.Rev., Vol. 18 (1982), pp. 151-162.

KLEINKNECHT, Theodor, "Die Beweisverbote im Strafprozeß“, NJW (1966), pp. 15371545.

KNOLL, Dieter, Die Fernwirkungen von Beweisverwertungsverboten, Augsburg: AVVerl., 1992.

LÖWE, Ewald, ROSENBERG, Werner, ERB, Volker, ESSER, Robert, FRANKE, Ulrich, GRAALMANN-SCHEERER, Kirsten, HILGER, Hans, IGNOR, Alexander, GERBER, Friederike, Die Strafprozeßordnung und das Gerichtsverfassungsgesetz: Großkommentar, Berlin; New York: de Gruyter, 2016.

MUELLER, Gerhard, "Beweisverbote im amerikanischen Strafprozeß", en: Comisión permanente de las jornadas alemanas de Derecho Verhandlungen des 46. Deutschen Juristentages, Band I (Gutachten), Teil 3A, München, Berlin: C.H. Beck, 1966, pp. 33-54.

OAKS, Dallin H., "Studying the Exclusionary Rule in Search and Seizure", U. Chi. L. Rev., Vol. 37, Nr. 4 (1970), pp. 665-757.

OSSENBERG, Sarah, Die Fernwirkung im deutsch-U.S.- amerikanischen Vergleich: unter bedonderer Berücksichtigung der Funktionen der Beweisverwertungsverbote, Hamburg: Kovac, 2011. 
PAULUS, Rainer, "Rechtsdogmatische Bemerkungen zum Urkundenbeweis in der Hauptverhandlung des Strafverfahrens", JuS t. 28 (1998), pp. 873-879.

PINO REYES, Octavio Alejandro, "Teoría de los efectos reflejos de la prueba ilícita o "teoría de los frutos del árbol envenenado", GJ (2011), pp. 26-37.

PITLER, Robert M.: "The Fruit of the poisonous Tree" Revisited and Shepardized", Cal. L. Rev., Vol. 56 (1968), pp. 579-651.

PITSCH, Christoph, Strafprozessuale Beweisverbote: eine systematische, praxisnahe und rechtsvergleichende Untersuchung unter besonderer Berücksichtigung des Steuerstrafverfahrens, der Zufallsfunde und der Fernwirkungsproblematik, Hamburgo: Kovac, 2009.

REICHERT-HAMMER, Hansjörg, “Zur Fernwirkung von Beweisverwertungsverboten (§136a StPO) - BHGSt 34, 362“, JuS (1989), pp. 446-450.

REINECKE, Jan, Die Fernwirkung von Beweisverwertungsverboten, München: VVF, 1990.

ROGALL, Klaus, "Beweisverbote im System des deutschen und des amerikanischen Strafverfahrensrechts", en: WOLTER, Jürgen; FEIGEN, Hanns W. (Ed.), Zur Theorie und Systematik des Strafprozeßrechts, Neuburg y otros: Hermann Luchterhand Verlag, 1995, pp. 113-160.

ROGALL, Klaus, "\$136a“", en: WOLTER, Jürgen. (Ed.), SK-StPO: Systematischer Kommentar zur Strafprozessordnung. Mit GVG und EMRK, Tomo II: $\$ \$ 94-136 a$ StPO, 5. Ed., Köln: Carl Heymanns Verlag, 2016.

ROGALL, Klaus, "Kernbereichsmystik im Strafverfahren", en: WESSLAU, Edda; WOHLERS, Wolfgang (Ed.), Festschrift für Gerhard Fezer zum 70. Geburtstag am 29. Oktober 2008, Berlin: De Gruyter, 2008, pp. 61-86.

ROXIN, Claus, Strafrecht: allgemeiner Teil Bd. 1 Grundlagen: der Aufbau der Verbrechenslehre, 4. Ed., München: Beck, 2006.

RIEUTORD ALVARADO, Andrés, El recurso de nulidad en el nuevo proceso penal, Santiago: Ed. Jurídica de Chile, 2007.

SCHLÜCHTER, Ellen, “Anmerkung zum Urteil des BGH vom 24.8.1983 - 3 StR 136/83 (BGHSt. 32, 68)““, JR (1984), pp. 517-522.

SCHRÖDER, Svenja, Beweisverwertungsverbote und Hypothese rechtmäßiger Beweiserlangung im Strafprozeß, Berlin: Duncker \& Humblot, 1992.

SENDLER, Horst, Die Verwertung rechtswidrig erlangter Beweismittel im Strafprozeß mit Berücksichtigung des anglo-amerikanischen und des französischen Rechts, Freie Universität Berlin, inédito, 1956.

TAVOLARI OLIVEROS, Raúl, Instituciones del nuevo proceso penal, Santiago: Editorial Jurídica de Chile, 2007.

WOHLERS, Wolfgang, "Fernwirkung - zur normativen Begrenzung der sachlichen Reichweite von Verwertungsverboten“, en: ZÖLLER, Mark A.; HILGER, Hans; KÜPER, Wilfried; ROXIN, Claus (Ed.), Gesamte Strafrechtswissenschaft in internationaler Dimension: Festschrift für Jürgen Wolter zum 70. Geburtstag am 7. September 2013, Berlin: Duncker \& Humblot, 2013, pp. 1181-1204.

WOLTER, Jürgen, “Anmerkung zum Urteil des BGH vom 24.08.1983 NStZ 1984, 275 ff.", NStZ t. 6 (1984), pp. 276-278.

ZAPATA GARCÍA, Francisca, La prueba ilícita, Santiago: Lexis Nexis, 2004. 
Polít. Crim. Vol. 14, No 28 (Diciembre 2019), Art. 5, pp. 186-214. [http://politcrim.com/wp-content/uploads/2019/11/Vol14N28A5.pdf] 